\title{
High temperature behavior of functional TiAlBSiN nanocomposite coatings
}

\author{
A.V. Pshyk ${ }^{\text {a,b,* }}$, L.E. Coy ${ }^{\text {a,** }}$, G. Nowaczyk ${ }^{\text {a }}$, M. Kempiński ${ }^{\text {a,c }}$, B. Peplińska ${ }^{\text {a }}$, A.D. Pogrebnjak ${ }^{\text {b }}$, \\ V.M. Beresnev ${ }^{\mathrm{d}}$, S. Jurga ${ }^{\mathrm{a}}$ \\ a NanoBioMedical Centre, Adam Mickiewicz University, Umultowska 85, 61-614 Poznań, Poland \\ b Sumy State University, 2, Rymskogo Korsakova St., 40007 Sumy, Ukraine \\ c Faculty of Physics, Adam Mickiewicz University, Umultowska 85, 61-614 Poznań, Poland \\ d Kharkiv National University, Kharkov, Ukraine
}

\section{A R T I C L E I N F O}

\section{Article history:}

Received 25 April 2016

Revised 25 July 2016

Accepted in revised form 26 July 2016

Available online 28 July 2016

\section{Keywords:}

Amorphous coating

Nanocomposite

Nanoindentation

Flexible protective coating

Tribology

\begin{abstract}
A B S T R A C T
This article reports on the thorough characterization of structural-phase transformation in amorphous TiAlBSiN coating after high temperature annealing at $900{ }^{\circ} \mathrm{C}$ in ambient air. The influence of annealing on the tribomechanical behavior of the coating at nano and micro scale was also examined. The research included multiple experimental techniques, i.e. AFM, SEM, TEM, HR-TEM, EDS, XPS and Raman spectroscopy. Experiments showed that the amorphous phase of the TiAlBSiN coating undergoes a structural transformation, evidenced in the changes of parameters such as topological and chemical short-range order after the post-deposition annealing at $900{ }^{\circ} \mathrm{C}$ in air. The observed structural transformation, leads to a phase separation with the formation of a three dimensional nc-TiAl $3 / \mathrm{a}-\mathrm{SiBN}(\mathrm{O})$ nanocomposite structure. The relative increase of hardness, reduced elastic modulus, $\mathrm{H} / \mathrm{Er}$ ratio and $\mathrm{H}^{2} / \mathrm{E}_{\mathrm{r}}^{3}$ ratio after high temperature treatment of TiAlBSiN coatings is also reported. The complex interdependency between chemistry, morphology and relative composition of the amorphous TiAlBSiN coating phase, during the high temperature treatment, with the respective change of the tribo-mechanical characteristics, are evidence of the improvement of the coating properties in response to the environmental conditions and high temperature. This work contributes particularly to the development and understanding of flexible nanocomposite protective coatings and their changes at high temperature of operation.
\end{abstract}

C 2016 Elsevier B.V. All rights reserved.

\section{Introduction}

The most widespread hard wear-resistant coatings are those with the following chemical formula Ti-X-(N/B/C) $(X=V, A l, W, S i, C, B$, etc.) which have proven to have excellent properties for industrial applications in the cutting and stamping tool industry [1-3]. In general, the increasing industrial demand for advanced coating systems with tailored properties, such as high hardness, good abrasive, sliding wear resistance, high temperature stability, as well as oxidation and corrosion resistance, have motivated researchers to continuously develop new quaternary and multinary based coating systems with exceptional combinations of functional properties [4-6]. The thermal stability of the majority of the hard protective coatings produced so far is relatively low, with a maximum operation temperature of approximately $1000{ }^{\circ} \mathrm{C}$ [7]. This level is insufficient for many applications, such as: tools for high speed cutting, aircraft engines, special parts of rockets and reusable

\footnotetext{
* Correspondence to: A.V. Pshyk, NanoBioMedical Centre, Adam Mickiewicz University, Umultowska 85, 61-614 Poznań, Poland.

** Corresponding author.

E-mail addresses: a.v.pshyk@gmail.com (A.V. Pshyk), coyeme@amu.edu.pl (L.E. Coy).
}

launch vehicles, which are exposed to temperatures up to $2000{ }^{\circ} \mathrm{C}$ [8-10]. The oxidation resistance of protective coatings gradually increases from binary compounds such as $\mathrm{TiC}\left(\sim 400{ }^{\circ} \mathrm{C}\right)$ and $\mathrm{TiN}$ $\left(\sim 650{ }^{\circ} \mathrm{C}\right)$, ternary compounds: TiAlN $\left(\sim 850{ }^{\circ} \mathrm{C}\right)$ and $\operatorname{TiSiN}\left(\sim 1000^{\circ} \mathrm{C}\right)$, to quaternary compounds: TiAlTaN $\left(\sim 850{ }^{\circ} \mathrm{C}\right)$ and TiAlSiN $\left(\sim 800^{\circ} \mathrm{C}\right)$, TiAlBN $\left(\sim 900{ }^{\circ} \mathrm{C}\right)$ and recently multielement compounds such as TiAlCrYN $\left(\sim 930{ }^{\circ} \mathrm{C}\right)$, CrAlSiBN $\left(\sim 1200{ }^{\circ} \mathrm{C}\right)$ and TiAlSiCN $\left(\sim 1300{ }^{\circ} \mathrm{C}\right)$, due to the doping of $\mathrm{Ti}-\mathrm{X}-(\mathrm{N} / \mathrm{B} / \mathrm{C})$ coating with suitable $\mathrm{X}$ element ( $\mathrm{X}=\mathrm{V}, \mathrm{Al}, \mathrm{W}, \mathrm{Si}, \mathrm{C}, \mathrm{B}$, etc.) and also, because of their changes in nanocrystalline structure $[5,11-14,15,16,17,18]$. However, the nanostructure can be considered a metastable phase, which means that when the operating temperature exceeds certain temperature, the nanostructure changes, specially grain size increases and amorphous phases crystallize within the coating layer. This process results in the destruction of the nanostructure and the formation of new crystalline phases. Nano- and microstructure of a coating are typically composed of grains separated by boundaries which have direct contact with an oxidative atmosphere. This fact determines the relatively low oxidation resistance of hard protective coatings at high temperatures [7]. Moreover, the crystallization of these protective coatings is the main reason for worsening of their mechanical properties at high temperatures. Therefore, it is important 
to achieve both a high temperature oxidation resistance as well as good thermal stability in order to develop hard protective coatings suitable for various applications.

An important approach suggests that the thermal stability and oxidation resistance of the protective coatings can be improved by the use of highly amorphous materials. [19,20]. It is well-known that amorphous materials contain no grains so there is no penetration of the atmosphere gases along the grain boundaries of the coating and additionally, reactions with the substrate are dramatically reduced. Following this idea, oxidation resistance of the coatings strongly depends on the thermal stability of its amorphous structure and the interdiffusion of the elements in both coating and substrate. The effect of substrate elements diffusing into the protective coating structure was reported in many papers [21-24]. It was shown that the crystallization starts directly at the coating/substrate interface due to the diffusion of substrate elements into the coating layer $[23,24]$. This interdiffusion can be avoided by placing a barrier layer between the substrate and the coating, which can also improve upon adhesion [25]. In the present work, we apply a sacrificial barrier layer between the substrate and the coating in order to investigate its applicability. The material of the sacrificial barrier can react with both, the elements of coating and the substrate, which could lead to its adaptation and resistance to the interdiffusion during high temperature annealing. In our approach, we deposited O-based multielement barrier layer in order to create a highly reactive layer, thanks to the high electronegativity of $\mathrm{O}$ and the amorphous material.

The combination of: corrosion resistance of AlN up to $1000{ }^{\circ} \mathrm{C}[26$, 27], electric conductance and superior physicomechanical properties of both $\mathrm{TiB}_{2}$ and $\mathrm{TiSi}_{2}$ makes the high temperature composite ceramic AlN-TiB $2-\mathrm{TiSi}_{2}$ a leading candidate that can meet the requirements for protective coatings for high temperature applications [28-31]. Bulk ceramics $\mathrm{AlN}_{-} \mathrm{TiB}_{2}-\mathrm{TiSi}_{2}$ display superior physicomechanical and tribological properties up to $1450^{\circ} \mathrm{C}$ [32], additionally, Si and B are metalloids which are very effective in stabilizing amorphous phases. Even relatively low concentration of Si can inhibit grain growth and stimulate the renucleation of grains in the presence of bias voltage at the substrate during deposition of TiAiN [33] and TiBN coatings [34]. Furthermore, the addition of small amount of Si significantly improves the thermal stability and oxidation resistance of TiAlN coatings [35]. B is known to be an even better choice for the amorphous phase formation and additionally, the incorporation of B into the coating leads to the systematic decrease of mass changes during oxidation processes at high temperatures [18, 36].

The aim of this article is to comprehensively investigate and understand the temperature stability and oxidation resistance of amorphous nanocomposite coatings deposited via DC magnetron sputtering of the high-temperature ceramic AlN-TiB 2 - $\mathrm{TiSi}_{2}$ target.

\subsection{Experimental details}

High-temperature ceramic $\mathrm{AlN}-\mathrm{TiB}_{2}-\mathrm{TiSi}_{2}$ target was sputtered via DC magnetron sputtering on stainless steel and $\mathrm{Si}$ (001) substrates. Substrates were cleaned in Ar plasma discharge for 15 min prior to deposition. High-temperature ceramic $\mathrm{AlN}-\mathrm{TiB}_{2}-\mathrm{TiSi}_{2}$ target of $70 \mathrm{~mm}$ diameter and $4 \mathrm{~mm}$ thick was synthesized from the powder mixture of $\mathrm{AlN}$ (50 wt.\%), $\mathrm{TiB}_{2}$ (35 wt.\%) and $\mathrm{TiSi}_{2}$ (15 wt.\%) by hot isostatic pressing at $1760-1780{ }^{\circ} \mathrm{C}$ [37]. The residual porosity of the target did not exceed $2 \%$. The deposition was performed using the following parameters of DC magnetron: the DC voltage applied to the sputtering target was $400 \mathrm{~V}$, current $\sim 200 \mathrm{~mA}$, argon pressure $0.078 \mathrm{~Pa}$, bias potential on the unheated substrate - $200 \mathrm{~V}$, magnetron current - $7.7 \mathrm{~A}$, substrate ion current density $\sim 1 \mathrm{~mA} / \mathrm{cm}^{2}$, cathode-substrate distance was $65 \mathrm{~mm}$. Deposition time was $90 \mathrm{~min}$ with a deposition rate of $\sim 11 \mathrm{~nm} / \mathrm{min}$. The barrier layer was deposited by means of reactive DC magnetron sputtering with the use of $5 \% \mathrm{O}_{2} / \mathrm{Ar}$ mixture. The obtained thickness of the TiAlSiBN coatings was approximately $1 \mu \mathrm{m}$.
The thermal stability and oxidation resistance were evaluated by means of structural-phase investigations and load-depth sensing nanoindentation measurements prior to and after annealing. The as-deposited coatings were annealed in air at $900{ }^{\circ} \mathrm{C}$. The annealing cycle consisted of 4 stages: heating up to $200{ }^{\circ} \mathrm{C}$ for $15 \mathrm{~min}$, heating up to $900{ }^{\circ} \mathrm{C}$ for $60 \mathrm{~min}$, annealing at $900{ }^{\circ} \mathrm{C}$ for $60 \mathrm{~min}$, cooling to $0{ }^{\circ} \mathrm{C}$ for $30 \mathrm{~min}$.

The evolution of structural, elemental and phase composition aspects of the obtained coatings were studied by means of atomic force microscopy (AFM), scanning and transmission electron microscopy, with energy dispersive analysis (SEM and TEM with EDS), X-ray photoelectron spectroscopy (XPS) and Raman spectroscopy. The morphology and structure of coating surface were studied using atomic force microscope Bruker Dimension Icon. The microstructure and elemental composition of coatings were examined by scanning electron microscope JEM-7001TTLS (JEOL) and transmission electron microscope ARM200F (JEOL). The preparation of cross-sectional samples for HR-TEM was carried out using focused ion beam system JIB-4000 (JEOL) with Ga ions. The current and voltage of the ion beam were gradually decreased during preparation starting from $10 \times 10^{3} \mathrm{pA}$ and $30 \mathrm{kV}$ to $23 \mathrm{pA}$ and $3 \mathrm{kV}$, respectively, in order to prevent the sample damage. The thin foil for TEM investigation was cut by FIB normal to sample surface. Thin carbon film was deposited prior to ion etching in order to prevent the sample damage.

The structure and chemical composition of the coating surfaces were analyzed by means of the X-ray photoelectron spectroscopy (XPS) technique mounted within the Omicron Nanotechnology multiprobe UHV system, using a monochromatized $\mathrm{Al}-\mathrm{K}_{\alpha} \mathrm{X}$-ray as the excitation source. XPS was conducted under ultrahigh vacuum $\left(10^{-10} \mathrm{mbar}\right)$. CasaXPS software was used to analyses the XPS data. Raman spectroscopy experiments were performed using Renishaw inVia confocal Raman microscope with $633 \mathrm{~nm}$ laser radiation. Spectra were recorded at laser power 50\% with 8-9 accumulations and exposition time was set to $10.00 \mathrm{~s}$.

The measurements of hardness $(\mathrm{H})$, reduced elastic modulus $\left(\mathrm{E}^{*}\right)$ and nanowear tests were carried out by load-depth-sensing nanoindentation method using a Hysitron TriboIndenter 950 equipped with a Berkovich diamond tip TI-0039 (conical angle $142.3^{\circ}$ and $100 \mathrm{~nm}$ tip radius) calibrated against the fused silica sample. Multicycling testing refers to the performance of the sequence of loading-unloading cycles in one experiment, thus saving time and providing improved repeatability. In each cycle, the unloading slope from the force-depth curve is analyzed by the Oliver and Pharr method in order to determine the coating hardness [38]. In principle, when the Oliver and Pharr method is utilized in the data processing for a coating, the obtained indentation hardness and modulus reflect not only the mechanical attributes of the coating, but also those of the underlying substrate. To circumvent this difficulty, a sequential-nanoindentation approach can be employed to obtain the "intrinsic' properties of the coating through data fitting [39]. The multiple load function in the form of trapezoidal sinus was applied to the indenter with step-by-step load changing starting from $0.05 \mu \mathrm{N}$ to $10 \mathrm{mN}$ (a segment of load lasted $3 \mathrm{~s}$, holding segment $0.5 \mathrm{~s}$ and unloading $3 \mathrm{~s}$ ) in order to measure the hardness $(\mathrm{H})$ and reduced elastic modulus $\left(E^{*}\right)$ of coating surfaces at different depth. Sample hardness and standard deviations are determined following the method described by Oliver and Pharr.

Nanowear tests were performed by raster single pass scanning of the sample area of $5 \mu \mathrm{m} \times 5 \mu \mathrm{m}$ with a constant force of $1000 \mu \mathrm{N}$ by means of Berkovich diamond tip. The wear volume was calculated as the square of the scan size multiplied by the measured wear depth. The latter was measured using the in-situ SPM imaging technique.

Tribological tests were conducted on a CSM Instruments Tribometer automated friction machine in air by a "ball-on-disc" scheme, at a temperature of $20^{\circ} \mathrm{C}$. A ball of $6 \mathrm{~mm}$ diameter made of the $\mathrm{Al}_{2} \mathrm{O}_{3}$ (certified sintered material) acted as the counter body. The coatings were applied to discs made of steel 45 ( $55 \mathrm{HRC}$ ) of $50 \mathrm{~mm}$ diameter and $5 \mathrm{~mm}$ thickness; test load was $3.0 \mathrm{~N}$, the sliding distance was $1200 \mathrm{~m}$ and the sliding rate was $10 \mathrm{~cm} / \mathrm{s}$. Alumina balls were chosen due to their chemical 
(a)

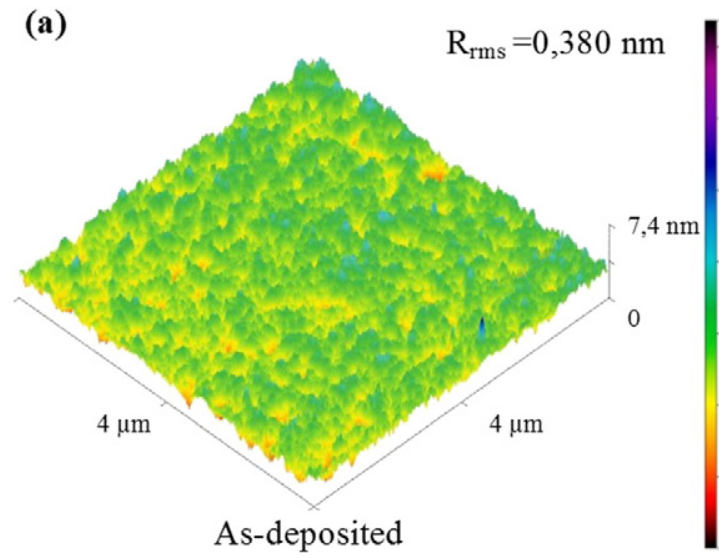

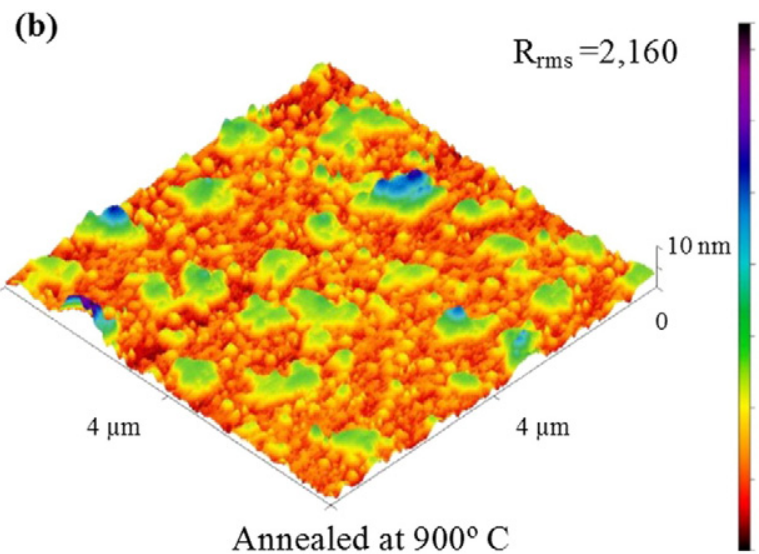

Fig. 1. Three-dimensional AFM surface morphologies and their surface roughness of as-deposited (a) and annealed at $900{ }^{\circ} \mathrm{C}$ (b) TiAlBSiN coating on silicon wafer substrate.

inertness and high hardness. Thus, only damage due to friction coming from the deposited coatings was observed. After the wear tests, worn surfaces of the tested samples were investigated with the scanning electron microscopy (SEM) and energy dispersive spectroscopy (EDS) in order to obtain information related to the wear mechanisms.

\section{Results and discussion}

\subsection{AFM studies}

Fig. 1 shows a 3D AFM image reflecting the surface morphology of the sample. In label represent the root-mean-square value, associated to the surface roughness $\left(R_{r m s}\right)$ of the TiAlSiBN coatings as deposited (Fig. 1a) and after annealing at $900{ }^{\circ} \mathrm{C}$ (Fig. 1b). The coating surface is very smooth after deposition, with $\mathrm{R}_{\mathrm{rms}}$ equal to $0.38 \mathrm{~nm}$ (measured over the area of $1 \times 1 \mu \mathrm{m}$ ). Such nano roughness indicates the good quality of the coatings produced by DC magnetron sputtering. Me-
Met-Ox (Me- metal, Met-metalloid) oxides formation during thermal annealing at $900{ }^{\circ} \mathrm{C}$, island growth and densification of the material, affecting the surface roughness were observed. Due to the growth, of islands perpendicular to the substrate surface, the roughness increased to $\mathrm{R}_{\mathrm{rms}}=2.16 \mathrm{~nm}$ after annealing. The surface roughness increases accompanied by a visible island growth, the roughness increased to $\mathrm{R}_{\mathrm{rms}}=2.16 \mathrm{~nm}$ after annealing. Nevertheless, although the high temperature of annealing used, not significantly affect were observed in the coating roughness, which is an important characteristic for coatings facing both, different friction condition during dry machining and high temperature impact.

\subsection{SEM studies}

Fig. 2a and $\mathrm{b}$ show the top-view and cross-section images of the TiAlBSiN coatings as-deposited and after annealed at $900{ }^{\circ} \mathrm{C}$ in air, respectively. From the top view image (Fig. 2a), the fine homogenous
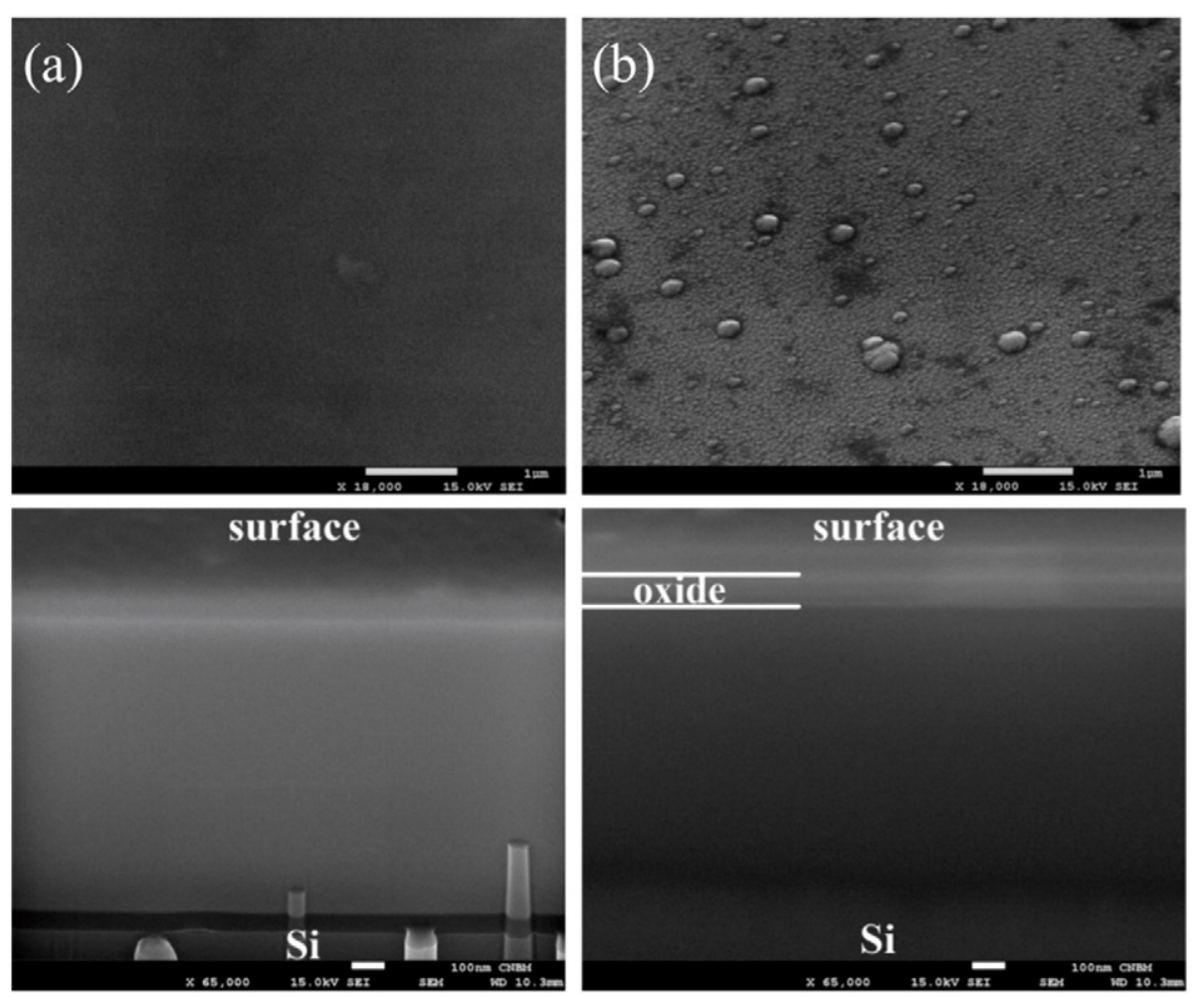

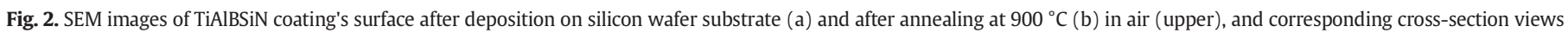
(lower). 


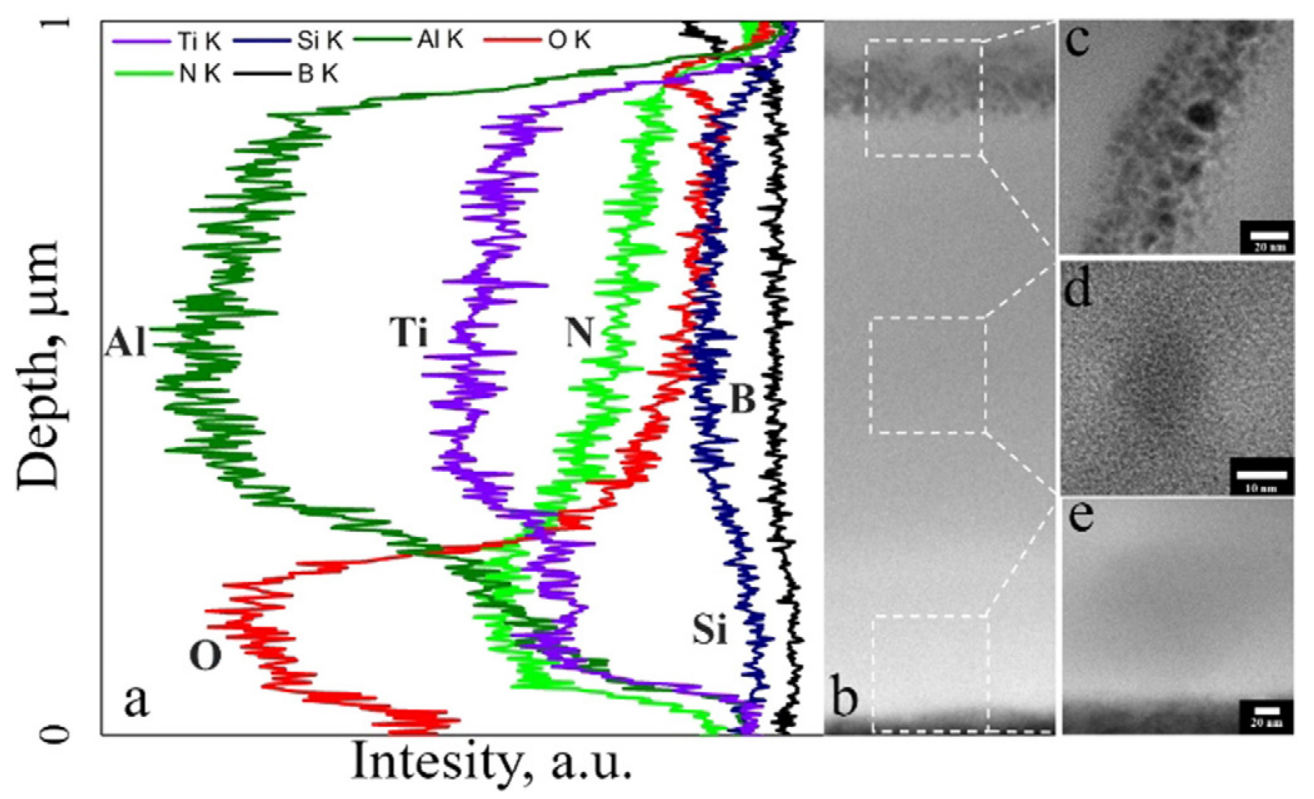

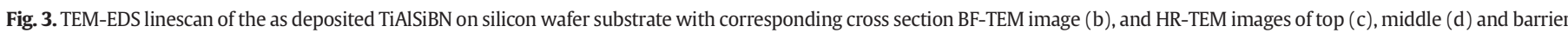
layer (e).

and uniform surface characteristics are observed for the as deposited coating. The cross-section image shows the dense and featureless structure of the as-deposited coating with a sharp coating/substrate interface. The high temperature annealing led to the formation of superficial globular oxide nodules and grains of $400 \mathrm{~nm}$. The structure of the coating appears to be preserved, but the formation of the surface oxide layer and diffuse interface with the substrate are observed.

\subsection{TEM-EDS studies}

Fig. 3a shows the extracted EDS profile of the as-deposited TiAlBSiN coating with the corresponding bright-field TEM (BF-TEM) image (b), and HR-TEM images of top (c), middle (d) and barrier layer (e). The as deposited coating shows fully amorphous structure as shown in the close magnification HR-TEM images. The coating microstructure is dense and void-free after the deposition, this. It means that the energy delivered to the growing coating was optimal due to relatively low deposition rate in combination with optimal values of the substrate bias and the substrate ion current density [40]. The amorphous state of the as-deposited TiAlBSiN coating is explained by the large difference in atomic size of the alloying elements and the different bond coordination, which is additionally constrain by the ion flux, ultimately restricting the grain growth. The TiAlBSiN coating exhibits 3-layer structure which can be identified on both the EDS lines can and BF-TEM image. The top layer of the coating is characterized by a relatively high oxygen concentration $~ 13.23$ at.\% (Table. 1 ) that indicates the oxidation of the surface starting from the room temperature, just after the deposition, and the formation of amorphous Me-Met-O at the outermost layer $(\sim 10 \mathrm{~nm})$. The region beneath the Me-Met-O surface layer is a $\sim 800 \mathrm{~nm}$ thick layer composed of $\mathrm{Al}$, Ti and $\mathrm{N}$ with lower signal from other target elements such as B and Si. Finally, the barrier layer is depleted of $\mathrm{Al}$ and $\mathrm{Ti}$, which could be explained by the characteristics of the sputtering process of a multiphase target during the reactive DC magnetron sputtering [41]. The O-rich barrier layer with amorphous structure serves as a "trap" for diffusive element from the both sides of the barrier. It limits elements of both, the coating and the substrate, due to the high electronegativity of $\mathrm{O}$ and amorphous structure.

Fig. 4 shows the analytical results of the structure transformation of TiAlBSiN coating after high temperature annealing in oxidative ambient at $900{ }^{\circ} \mathrm{C}$. The EDS lines scan (Fig. 4a) and EDS quantitative analysis indicates that $\mathrm{Al}$, Ti and $\mathrm{N}$ diffuses outwards, toward the free surface of the coating, which causes its non-uniform distribution through the depth of the coating. The layering becomes more evident and the surface oxide layer increases to $35 \mathrm{~nm}$, with a small amount of $\mathrm{Al}$ and Ti. The oxide surface protects the underneath layer from degradation and oxidation as shown by the low oxygen content on the $\mathrm{O}$ concentration profile, which at the coating/barrier layer, remains relatively unchanged after annealing, whereas a slight increase of $\mathrm{Al}, \mathrm{Ti}, \mathrm{Si}$ and $\mathrm{O}$ concentration in the barrier layer is observed. This increment is due to the exchange of diffusion elements to the sacrificial barrier from the coating and the $\mathrm{Si}$ substrate. The Si content in the coating increases to 3.3 at.\% after annealing, while the Si concentration increases (6.59 at.\%) in comparison with the barrier layer just after the deposition. This indicates that the barrier layer suppresses the $\mathrm{Si}$ diffusion to the coating, but does not fully stop it, showing the effectiveness and stability of $\operatorname{TiAlBSiN}(\mathrm{O})$ sacrificial barrier layer at $900{ }^{\circ} \mathrm{C}$ with presence of interdiffusion between coating/barrier/ substrate.

The barrier layer shows a significant mixing behavior within its volume after annealing. The formation of the outermost Ti-rich layer at the coating/barrier interface is well pronounced, layer that is probably

Table 1

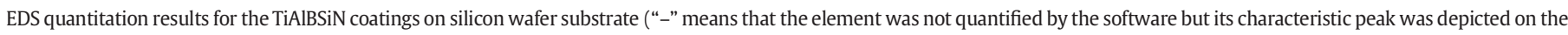
EDS spectrum).

\begin{tabular}{|c|c|c|c|c|c|c|c|c|}
\hline & & Thickness, nm & Ti, at.\% & $\mathrm{Al}$, at.\% & $\mathrm{Si}$, at.\% & O, at.\% & $\mathrm{N}$, at.\% & B, at.\% \\
\hline \multirow[t]{3}{*}{ As-deposited } & Top oxide & $\sim 10$ & 12.66 & 24.05 & 3.96 & 13.23 & 10.04 & 36.05 \\
\hline & Coating & $\sim 800$ & 13.28 & 23.59 & 4.20 & 9.51 & 12.01 & 37.41 \\
\hline & Barrier layer & $\sim 200$ & 11.00 & 11.40 & 4.20 & 49.82 & - & 23.58 \\
\hline \multirow[t]{3}{*}{ Annealed at $900{ }^{\circ} \mathrm{C}$} & Top oxide & $\sim 35$ & 12.52 & 14.54 & 6.64 & 66.30 & - & - \\
\hline & Coating & $\sim 800$ & 22.21 & 28.97 & 7.50 & 29.10 & 12.22 & - \\
\hline & Barrier layer & $\sim 200$ & 11.34 & 12.16 & 10.79 & 65.71 & - & - \\
\hline
\end{tabular}




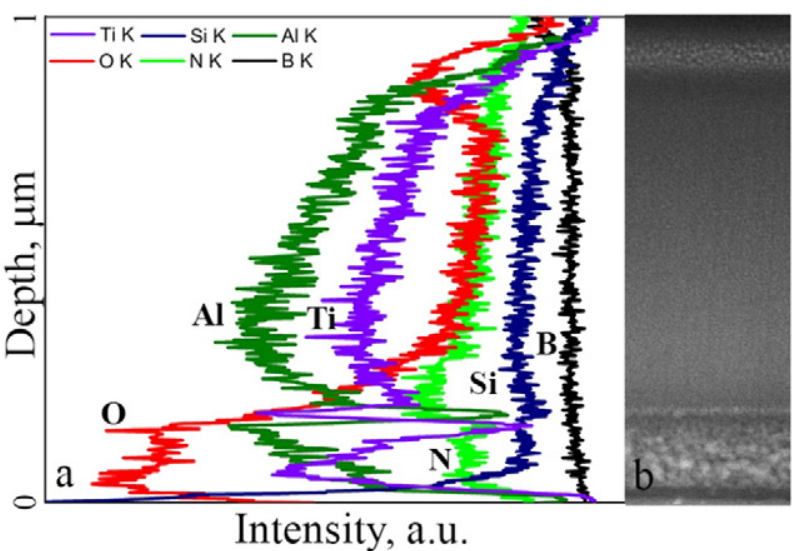

Fig. 4. TEM-EDS linescan of TiAlSiBN on silicon wafer substrate after oxidation in ambient air at $900{ }^{\circ} \mathrm{C}$ (a) with corresponding cross section dark-field TEM image (b).
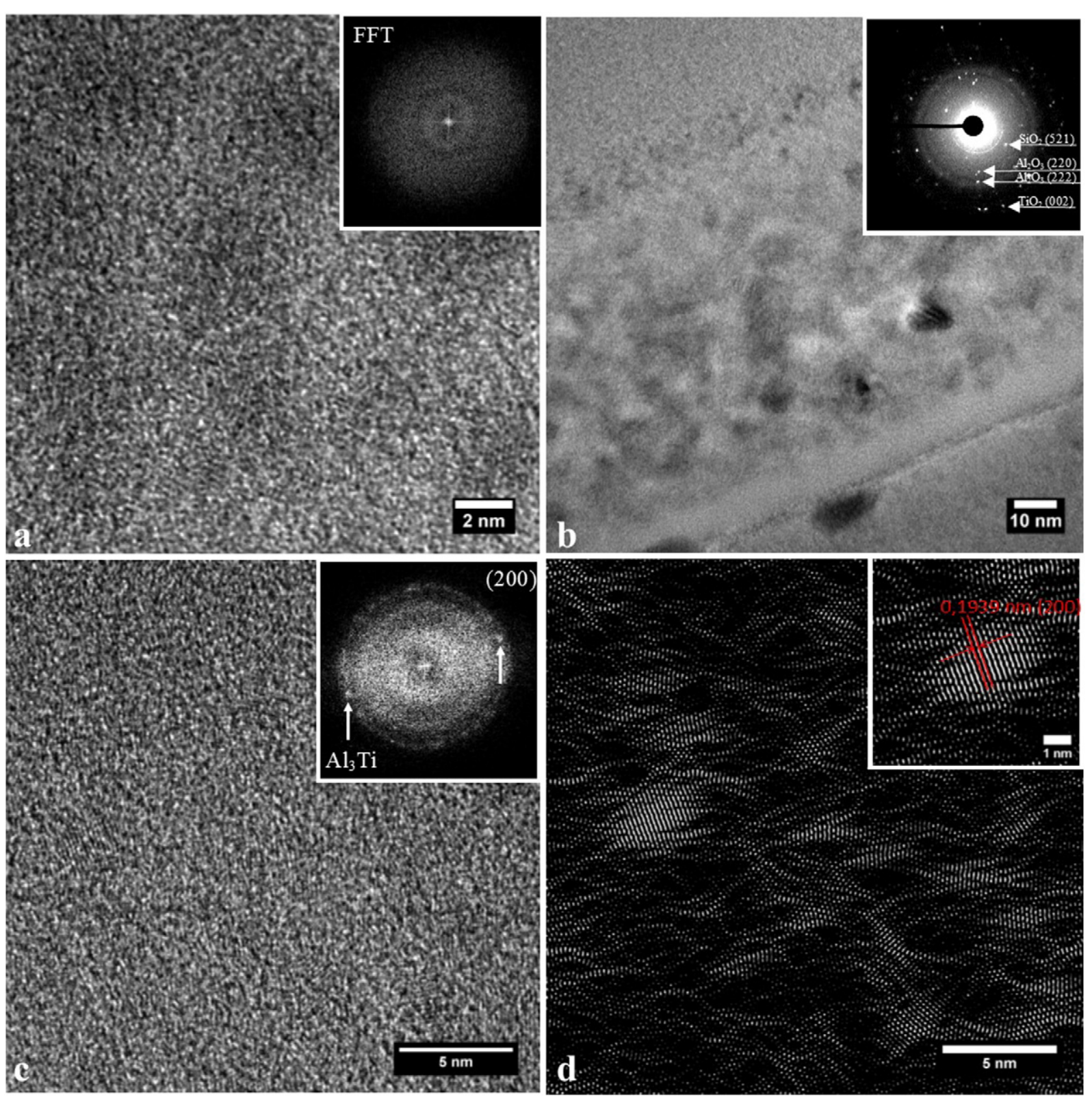

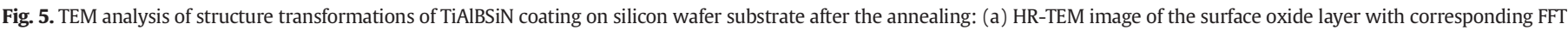

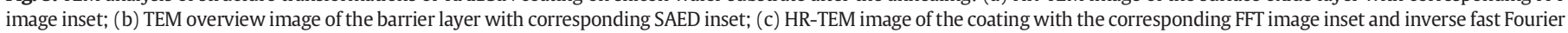

transform (IFFT) image of (c) with zoomed image of the $\mathrm{Al}_{3} \mathrm{Ti}$ nanograin. rier/substrate interface is based on Ti and depleted of Al. The layered formation of the oxide layers in the barrier volume can be related to the standard enthalpy of formation and the diffusion coefficients of the participating elements. At the initial stages of the annealing, the thermodynamically more favorable $\mathrm{Al}_{2} \mathrm{O}_{3}\left(\Delta \mathrm{G}=-1675.7 \mathrm{~kJ} / \mathrm{mol}^{-1}\right.$ [42]) starts to form first. Considering that the diffusivity of Ti in alumina is very low, even can be negligible at $350-700{ }^{\circ} \mathrm{C}, \mathrm{TiO}_{2}$ $\left(\Delta \mathrm{G}=-944.0 \mathrm{~kJ} / \mathrm{mol}^{-1}[42]\right)$ it then forms at both sides of the $\mathrm{Al}_{2} \mathrm{O}_{3}$. Due to the Ti out-diffusion from the coating toward the barrier and the diffusion inside the barrier, the concentration gradients of $\mathrm{Ti}$ and $\mathrm{O}$ is high enough for the $\mathrm{TiO}_{2}$ nucleation and therefore its apparition can be expected.

More detailed analysis of TiAlBSiN coating's structure transformations after the high temperature annealing at $900{ }^{\circ} \mathrm{C}$ was carried out by means of HR-TEM. Fig. 5 a does not show clear evidence of crystallization of the surface oxide layer of the TiAlBSiN coating and the FFT inset clearly shows its pure amorphous state. The coating microstructure 
remains dense and void-free after the annealing. The cross-sectional view of the barrier layer reveals its crystallization after the annealing and the formation of a dense amorphous interface with the substrate, due to the Si diffusion from the substrate (Fig. 5b). The barrier/coating interface does not show a well-pronounced boundary that confirms interdiffusion between these two parts of the coating. The selected area electron diffraction (SAED) pattern of the barrier layer (inset Fig. 5b) shows the diffraction spots that are attributed to $\mathrm{SiO}_{2}, \mathrm{Al}_{2} \mathrm{O}_{3}$ and $\mathrm{TiO}_{2}$. The size of these nanocrystals were estimated to be $8-15 \mathrm{~nm}$ range.

The presented HR-TEM image of the TiAlBSiN coating clearly shows a small crystal surrounded by the disordered regions (Fig. 5c). The fast Fourier transform (FFT) pattern taken from image Fig. 5c (Fig. 5c inset) displays the broad diffuse halo ring, corresponding to the disordered phase and two characteristic spots corresponding to a crystalline region. The region could be assigned to (200) $\mathrm{Al}_{3} \mathrm{Ti}$. The corresponding IFFT image confirms the presence of $\mathrm{Al}_{3}$ Ti nanograins (bright areas) with size ranging from 2 to $3 \mathrm{~nm}$ surrounded by $\operatorname{SiBN}(\mathrm{O})$ amorphous tissue phase (dark areas). The volume fractions of the crystalline and the amorphous phases in the coating are estimated based on IFFT of HR-
TEM image analysis to be $\sim 30 \%$ and $~ 70 \%$, respectively. The observed regions of bright disordered areas (non-crystalline) and dark areas arise due to different scattering vector of these areas, which indicates different short range order. Consequently, the $\operatorname{SiBN}(\mathrm{O})$ amorphous matrix is composed of different types of nanoclusters which are locally ordered and separated by the intercluster boundaries composed of irregularly ordered atoms. Thus, as a result of the amorphous phase transformation, a phase separation takes place during the heat treatment, forming two amorphous phases with different degree of the short range topological order. The central part of the $\mathrm{TiAl}_{3}$ nanograin (zoomed image in the inset Fig. 5d) has the ideal crystalline structure which changes to amorphous at the periphery of the grain. The amorphous phase has no sharp boundaries with nanocrystalline phase. It is important to note that bright elongated areas on the IFFT image (Fig. 5d) indicate that the process of ordering of the amorphous material into the nanoclusters with subsequent grain growth took place during the thermal treatment as a result of the diffusion processes leading to the formation of regions with different elemental compositions and different shortrange orders.
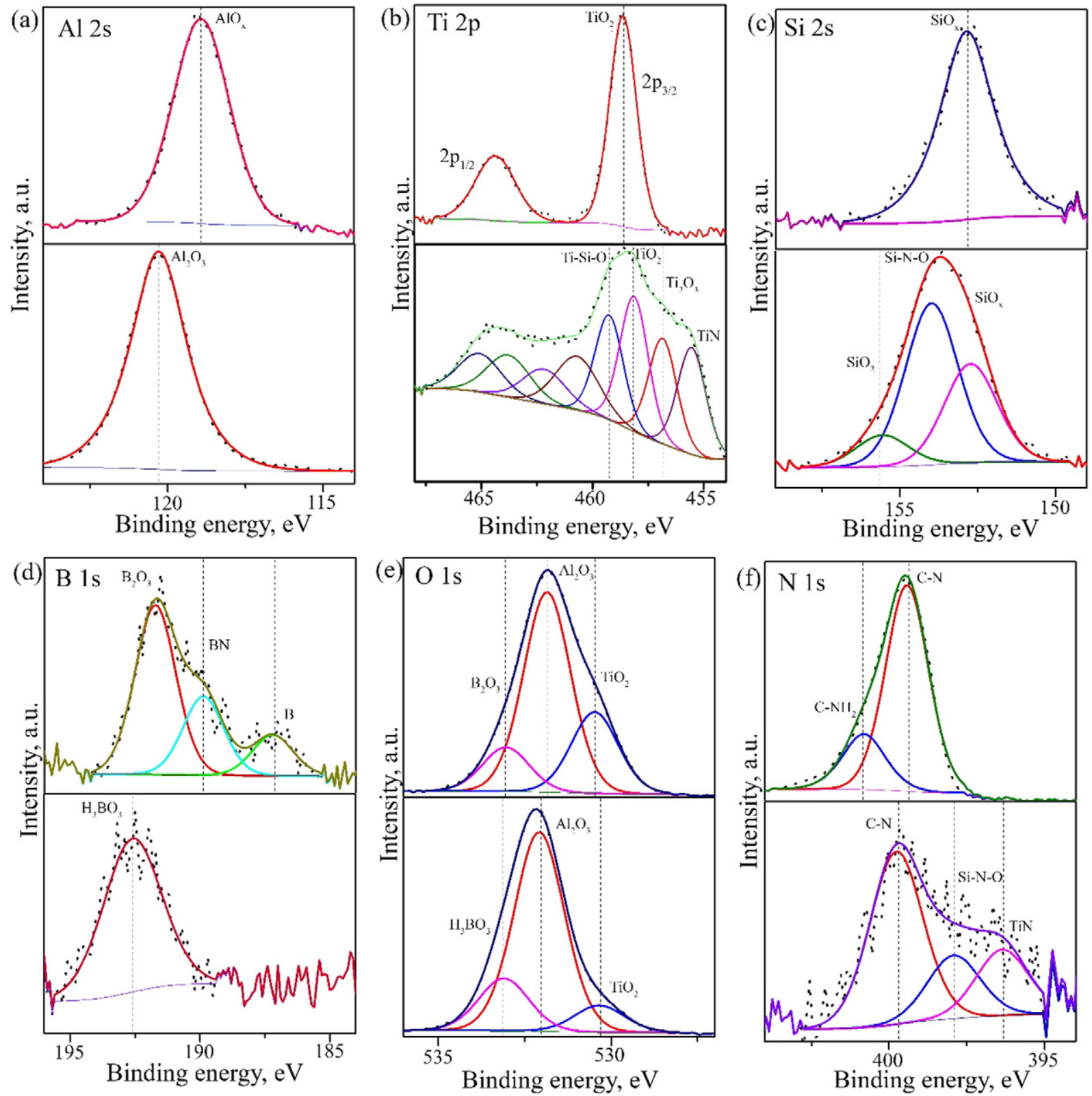

Fig. 6. XPS spectra of the TiAlBSiN coatings on silicon wafer substrate. Upper spectrum - as-deposited coating, lower spectra - after annealing at $900{ }^{\circ} \mathrm{C}$. 


\subsection{XPS studies}

In order to better understand the formation of chemical boundings, quantitative elemental composition and chemical binding states of the TiAlBSiN coatings, pre and post annealing, were studied by XPS. Typical $\mathrm{Al}$ 2s, Ti 2p, Si 2s, B 1s, O 1s and N 1s XPS spectra of the amorphous surface layer of the as-deposited TiAlBSiN coating (upper) and the coating after annealing at $900{ }^{\circ} \mathrm{C}$ (lower) are presented in Fig. 6. The bulk composition of the as-prepared sample was determined to be non-stoichiometric $\mathrm{Ti}_{0.07} \mathrm{Al}_{0.24} \mathrm{~B}_{0.21} \mathrm{Si}_{0.03} \mathrm{~N}_{0.28} \mathrm{O}_{0.17}$. After annealing the elemental composition of the surface layer was stabilized at $\mathrm{Ti}_{0.04} \mathrm{Al}_{0.3} \mathrm{~B}_{0.04} \mathrm{Si}_{0.02} \mathrm{~N}_{0.1} \mathrm{O}_{0.5}$. The slight discrepancy in the composition of the top layer determined by means of EDS and XPS can be attributed to either the different characteristic depths of the methods or to the overlapping of the EDS signals from the light elements.

The $\mathrm{Al}$ 2s spectrum of the surface of the as-prepared TiAlBSiN coating (Fig. 6a, upper) shows the characteristic band at $118.9 \mathrm{eV}$, which could be attributed to the non-stoichiometric oxidized $\mathrm{AlO}_{\mathrm{x}}$ phase [43], whereas the high temperature oxidation at $900{ }^{\circ} \mathrm{C}$ caused the shift of the peak toward the higher binding energy $120.29 \mathrm{eV}$, that is attributed to the stoichiometric $\mathrm{Al}_{2} \mathrm{O}_{3}$ phase [44]. The Ti 2p spectrum of the surface of the as-prepared coating (Fig. $6 \mathrm{~b}$, upper) presents the asymmetrical Ti $2 \mathrm{p}_{3 / 2}$ and Ti $2 \mathrm{p}_{1 / 2}$ doublets (458.6 eV and 464.35, respectively) which matches the $\mathrm{TiO}_{2}$ phase [45]. The annealing of the coating led to the broadening of the asymmetrical Ti $2 \mathrm{p}_{3 / 2}$ and $2 \mathrm{p}_{1 / 2}$ doublets of the Ti $2 \mathrm{p}$ spectra. The Ti $2 \mathrm{p}$ spectra were deconvoluted into 4 spin-orbit doublets which could be attributed to $\mathrm{Ti}-\mathrm{Si}-\mathrm{O}$ (459.25 eV [46]), $\mathrm{TiO}_{2}$ (458.1 eV [47]), $\mathrm{Ti}_{2} \mathrm{O}_{3}$ (456.85 eV [47]), $\mathrm{Ti}-\mathrm{N}$ (455.54 eV [48]) bonds.

The $\mathrm{Si} 2 \mathrm{~s}$ spectrum of the as-deposited coating could be due to SiOx contribution (152.7 eV [49]). After annealing, the broadening of the spectrum is observed, which could be fitted using three peaks located at $152.7 \mathrm{eV}, 154.0 \mathrm{eV}$ and $155.65 \mathrm{eV}$. The first peak was attributed to $\mathrm{SiOx}$ bonds while the second peak originates from $\mathrm{Si}-\mathrm{N}-\mathrm{O}$ bonds [45]. The peak at $155.65 \mathrm{eV}$ is typical for $\mathrm{SiO}_{2}$ [49].

The B 1s spectra of the surface of the as-deposited TiAlBSiN coating were deconvoluted using three peaks positioned at $187.11 \mathrm{eV}$, $189.88 \mathrm{eV}$ and $191.7 \mathrm{eV}$, which were attributed to B, B-N [50] and $\mathrm{B}_{2} \mathrm{O}_{3}$, respectively (Fig.6d, upper) [51]. After the heat treatment, a significant decrease of B 1s intensity, with a shifting to higher binding energies, $192.58 \mathrm{eV}$, was detected. This can be assigned to the formation of boric acid $\mathrm{H}_{3} \mathrm{BO}_{3}$ at the surface of the coating $[52,53]$.

The $01 \mathrm{~s}$ spectrum can be fitted with three components, Fig. 6e. The main component at around $531.8 \mathrm{eV}$ can be associated with $\mathrm{Al}_{2} \mathrm{O}_{3}$ [54]. Other minor components at around $530.47 \mathrm{eV}$ and $533.0 \mathrm{eV}$ can be associated to $\mathrm{TiO}_{2}$ and $\mathrm{B}_{2} \mathrm{O}_{3}$ bonds, respectively [55]. The spectrum of the surface after annealing did not change significantly, except the peak at $533 \mathrm{eV}$, which was shifted to $533.2 \mathrm{eV}$ that can be attributed to the formation of $\mathrm{H}_{3} \mathrm{BO}_{3}$ [45].

The $\mathrm{N} 1 \mathrm{~s}$ spectrum of the coating's surface after deposition is fitted with two peaks (Fig. 7f, upper). The most intense peak at $399.43 \mathrm{eV}$ can be attributed to $\mathrm{C}-\mathrm{N}$ [56] contaminations whereas the low intense peak at 400.86 to $\mathrm{C}-\mathrm{NH}_{2}$ [57]. The annealing of the coating caused the decrease of the $\mathrm{N} 1 \mathrm{~s}$ component intensity with arising of peaks at $397.9 \mathrm{eV}$ and $396.3 \mathrm{eV}$, which could be due to $\mathrm{Si}-\mathrm{N}-\mathrm{O}$ and $\mathrm{Ti}-\mathrm{N}$ bonds, respectively [45].

A common feature of the XPS spectra of the coating after annealing is the broadening of Ti, Si, N and O spectra and decreasing of Ti, B, Si, and N intensity. The former is considered to be due to the solid-state reactions at the surface between the constituent elements as a result of their diffusion toward the surface. Moreover, during the high temperature oxidation, the surface layer serves as the interface between the coating and ambient atmosphere where the mixing process of $\mathrm{O}$ and the coating's elements occurs. On the other hand, it is well known, that $\mathrm{Al}$ diffusion rate in $\mathrm{Al}_{2} \mathrm{O}_{3}$ at $900{ }^{\circ} \mathrm{C}$ is higher than that of $\mathrm{O}$ [58], so it is likely that $\mathrm{Al}$ diffuses through the $\mathrm{Al}_{2} \mathrm{O}_{3}$ as well and oxidizes near the free surface,

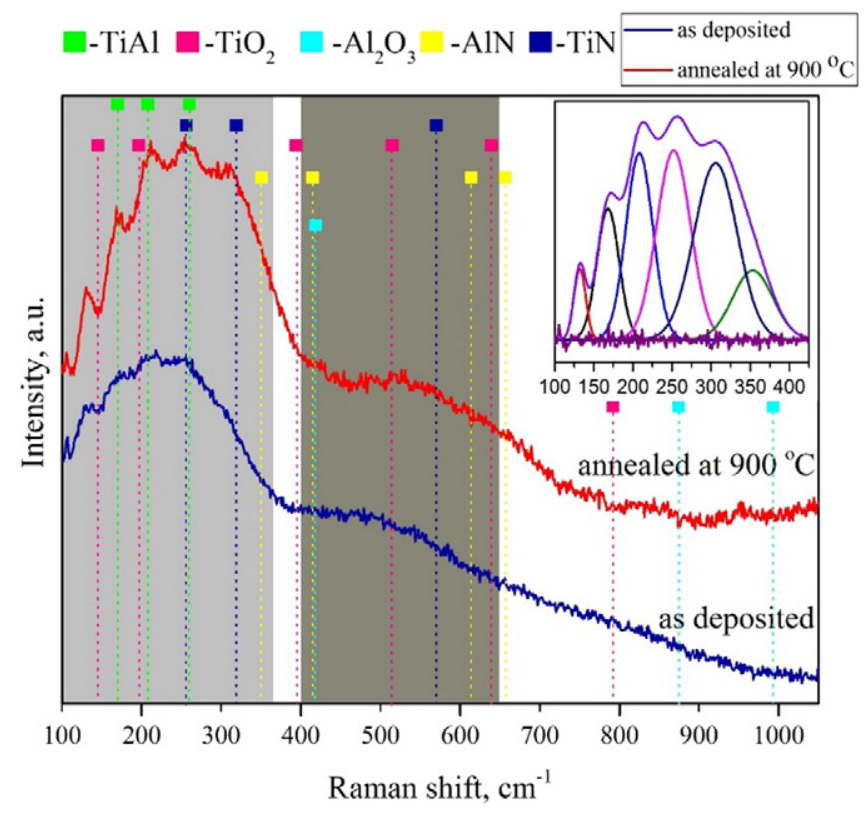

Fig. 7. Raman spectra of the as-deposited TiAlBSiN coating (blue) and the coating after annealing (red) on the silicon wafer substrate. The fitting of the low-frequency spectrum part of the annealed coating is shown in the insert.

whereas diffusivity of Ti in alumina is very low. Thus, due to the $\mathrm{Al}_{2} \mathrm{O}_{3}$ overgrowth, Ti, $\mathrm{B}$, and $\mathrm{N}$ containing bonds give low contribution to the intensity of the signals. Besides, $\mathrm{N}$ was reported to be released from the coatings during annealing [23]. Moreover, the $\mathrm{B}$ loss could be attributed to the reaction with the residual $\mathrm{O}$ to form a surface $\mathrm{B}_{2} \mathrm{O}_{3}$ layer which transforms, in the presence of residual moisture, to volatile boric acid $\mathrm{H}_{3} \mathrm{BO}_{3}$ (Fig. 6d, lower) which subsequently evaporates [52]. The latter, in addition to the $\mathrm{Al}_{2} \mathrm{O}_{3}$ overgrowth, explains the evolution of the surface roughness after the annealing (Fig. 1b).

As revealed by HR-TEM, the surface layer tends to grow remaining in the amorphous state during the high temperature annealing. This process in our case is due to the synergetic effect of the kinetic factors given by the continuous interdiffusion of the constituting elements with the large difference in atomic size $\left(\mathrm{r}_{\mathrm{Ti}}=0.140 \mathrm{~nm}, \mathrm{r}_{\mathrm{N}}=\right.$ $0.065 \mathrm{~nm}, \mathrm{r}_{\mathrm{Si}}=0.110 \mathrm{~nm}, \mathrm{r}_{\mathrm{Al}}=0.125 \mathrm{~nm}, \mathrm{r}_{\mathrm{B}}=0.085 \mathrm{~nm}$ and $\mathrm{r}_{\mathrm{O}}=$ $0.06 \mathrm{~nm}$ ) and variety of possible bonds coordination. The difference in diffusion rate of the constituent elements and the lack of time for a reorganization of the atomic orbital among the reactive atoms and subsequent reorganization of elements along the lattice of the crystalline phase led to growth of the amorphous phase. The thermodynamic driving force of the amorphous layer growth in this case can be based on the large negative heat of mixing and hence the low free energy of the amorphous phase $[59,60]$.

\subsection{Raman studies}

The structural transformations of the TiAlSiBN coatings were additionally characterized using Raman spectroscopy. Raman is a powerful tool to study transitions where changes on a short length scale take place and hence crystallization-induced short-range structural order changes during the high temperature treatment can be elucidated.

The previous Raman studies of TiN [61], TiAlN [62] and more recently nanocomposite TiAlSiCN [11] coatings revealed the scattering in the acoustic range $150-350 \mathrm{~cm}^{-1}$ (transitional and longitudinal acoustic vibrations - TA and LA, respectively) is determined primarily by the vibration of heavy ions near non-metallic vacancies, and that in the optical range $400-650 \mathrm{~cm}^{-1}$ (transitional and longitudinal optical vibrations 
- TO and LO, respectively) arises from the vibration of light atoms adjacent to metallic vacancies.

The Raman spectra of the as-deposited TiAlSiBN coating and those annealed at $900{ }^{\circ} \mathrm{C}$ are shown in Fig. 7. The spectrum of the asdeposited coating displays broad peaks caused by transitions in the acoustic frequency region and another set of lines resulting from the optical modes. Spatial order in the positioning of atoms in a material with amorphous structure has topological nature while the ordering of different types of atoms in the multicomponent systems has chemical or compositional nature [63]. The imperfections of the amorphous structure, such as imperfect atom coordination, fluctuations of free volume, regions of large shear stresses, vacancies and pseudo-vacancies, n-, pand $\tau$-defects [64,65], forced us to adopt the conclusion that the richness of the possible defects and multiplicity of chemical bonds envisaged in the topological and chemical short-range order of the amorphous multi-element TiAlBSiN coating, is probably reflected in the multiplicity of the vibrational lines illustrated in the acoustic and optical range (red spectrum in Fig. 7). In compliance with the Hooke's law (the lighter the atoms, the higher their vibration frequency will be) the first-ordered acoustic lines are related to the vibrations of Ti and $\mathrm{Al}$ atoms near $\mathrm{N}, \mathrm{B}$ and $\mathrm{O}$ vacancies, while the broad first-ordered optical band arises from vibration of the light atoms adjacent to Ti and Al vacancies. This result is in the good agreement with the Raman spectra reported before for the amorphous TiAlN/TiAlSiN $/ \mathrm{Si}_{3} \mathrm{~N}_{4}$, AlTiON and AlTiO coatings [66-68].

The analysis of the after annealing spectrum (Fig. 7, red line) showed that the drastic changes in the peak intensities of the first-order acoustic lines take place, implying the interplay between the species of the coating (structural units). In order to proceed to the quantitative determination of the temperature dependence of the Raman spectra as well as the amorphous to nanocrystalline transition it is imperative to use a peak fitting procedure with the aim of separating individual vibrational modes (inset Fig. 7). The Raman spectrum displays sharp modes in acoustic frequency region, related to changes in the parameters of the chemical short-range order. The signal at $120 \pm 4 \mathrm{~cm}^{-1}$ is due to Ti-Ti vibrations. The strongest peaks located at $170 \pm 4,210 \pm 4,255 \pm$ $4 \mathrm{~cm}^{-1}$ can be attributed to Ti-Al vibrations which agrees with [69]. In addition, the band at $255 \pm 4$ could be the combination of two individual peaks due to $\mathrm{Ti}-\mathrm{Al}$ vibration and non-stoichiometric $\operatorname{TiN}_{\mathrm{x}}$ whose characteristic peak is positioned at $308 \pm 4 \mathrm{~cm}^{-1}$ as well [61]. The low intense peak at $350 \pm 4 \mathrm{~cm}^{-1}$ could be attributed to the Ti- $\mathrm{B}$ or Al-N vibrations [70,71]. The characteristic peak of $\mathrm{Al}_{2} \mathrm{O}_{3}$ at $423 \mathrm{~cm}^{-1}$ [72] gives the evidence of the oxidation of the coating's surface. Taking into account that the Raman intensity of a vibrational mode depends on the relative fraction of the species, it is evident that the phase segregation of the different components arises due to structural transformation of the amorphous phase. Besides, short-range ordered species (nanoclusters) of the amorphous phase react with neighboring irregularly ordered atoms and clusters with subsequent coalescence and grow, what leads to the increase of the Raman intensity of the corresponding components [73]. Thus, the peak sharpening of the acoustic lines could be attributed to the formation of the nano-crystalline structure with the high concentration of grain boundaries which, due to their specific surface and interface at grain boundaries, strongly contribute to the vibrational modes [74]. Correspondingly, the measured positions of the most intense lines in the acoustic region could be attributed to the vibration of metallic atoms at the nanograin boundaries adjusted to the lighter atoms of the amorphous tissue. Whereas the less intensive vibration lines in this region could be related to the vibration of the short-range ordered metallic components (clusters) of the amorphous phase adjusted to the light irregularly ordered atoms. The broad band in the optical region could be attributed to the vibration of the light atoms of the amorphous tissue at the interface with grain boundaries.

It is important to note that the structure of an amorphous phase is not in the equilibrium state. Being in initial metastable state, the amorphous phase tends to the transformation to metastable state upon heating with a local minimum of free energy. The structural transformation of the amorphous phase includes decrease in the free volume and changes in the parameters of the topological and chemical short-range order [75]. The structural transformations of the amorphous phases after the heat treatment due to the irreversible relaxation that related to changes in topological short-range order have been revealed by means of HR-TEM, whereas the reversible relaxation is revealed by means of Raman spectroscopy.

The Raman results coupled with the HR-TEM investigation allows us to conclude that the base part of the amorphous TiAlBSiN coating undergoes the phase separation with formation of the three dimensional nc- $\mathrm{TiAl}_{3} / \mathrm{a}-\mathrm{SiBN}(\mathrm{O})$ nanocomposite structure after post-deposition annealing at $900{ }^{\circ} \mathrm{C}$ in air. The observed separation into two amorphous phases with different short range order (Fig. 5) is due to the complex composition of the coating and the presence of several phases in this concentration range in the equilibrium phase diagram of Ti-Al- $\mathrm{N}$ [76] and $\mathrm{Ti}-\mathrm{Al}-\mathrm{O}$ [77] system which is basic for TiAlBSiN coating. Furthermore, the stability of the amorphous phase of the TiAlSiBN coating could be associated with the content of Si and B atomic species, which due to the reduced diffusion mobility, were suggested to inhibit growth of oxide grains and to decrease the mass change of the coatings during oxidation $[78,79]$.

The results on oxidation resistance of amorphous TiAlSiBN coatings reported previously [80] demonstrate the full oxidation after air annealing at $900{ }^{\circ} \mathrm{C}$ for $4 \mathrm{~h}$, with the formation of several oxide layers of mixed rutile- $\mathrm{TiO}_{2}+\mathrm{Al}_{2} \mathrm{O}_{3}$ and $\mathrm{TiN}$ phases with average grain size of 100 $200 \mathrm{~nm}$ and 10-45 nm, respectively. Their lower oxidation resistance in comparison to the TiAlBSiN coatings reported in this work, could be associated with the higher concentration of $\mathrm{Ti}$ and $\mathrm{Al}$ (B concentration was not reported in [80]) in combination with a longer oxidation time that promoted the growth of the corresponding oxides. The formation of $\mathrm{TiO}_{2}$ was already observed after oxidation at $800{ }^{\circ} \mathrm{C}$ for $1 \mathrm{~h}$ of amorphous TiAlSiBN coatings with further nucleation of $\mathrm{TiBO}_{3}, \mathrm{TiN}_{\mathrm{x}} \mathrm{O}_{\mathrm{y}}$ and $\mathrm{Ti}_{\mathrm{x}} \mathrm{Al}_{\mathrm{y}} \mathrm{SiO}_{\mathrm{z}}$ at $900{ }^{\circ} \mathrm{C}$ with the inward diffusion of $\mathrm{O}$ up to the depth of $800 \mathrm{~nm}$ [81]. Higher ratio of Ti/Al (29 at.\% of Ti and 6 at.\% of $\mathrm{Al}$ ) in the coating points at the formation of $\mathrm{TiO}_{2}$ at the surface which has worse barrier characteristics against $\mathrm{O}$ in comparison to $\mathrm{Al}_{2} \mathrm{O}_{3}$. Thus, having relatively the same concentration of $\mathrm{B}$ and $\mathrm{Si}$, the TiAlBSiN coatings reported in [81] had lower oxidation resistance at $900^{\circ} \mathrm{C}$.

\subsection{Nanoindentation tests}

The nanoindentation hardness $\mathrm{H}$ and reduced elastic modulus $\mathrm{E}_{\mathrm{r}}$ for the as-deposited and annealed coatings were measured under depth control mode at indentation depth of $80 \mathrm{~nm}$ ( $<10 \%$ of coating thickness) at the load of $3 \mathrm{mN}$. The hardness is the highest for the coating after annealing with $\mathrm{H}=24.41 \mathrm{GPa}$, followed by $\mathrm{H}=15.20 \mathrm{GPa}$ for the as deposited coating. The reduced elastic modulus follows the same trend with the highest value, $E_{\mathrm{r}}=212.46 \mathrm{GPa}$ for the coating after annealing, whereas for the as-deposited coating, it is slightly lower $\mathrm{E}_{\mathrm{r}}=177.6 \mathrm{GPa}$. The elastic recovery of the coatings estimated from the loadingunloading curves (not showed) was $61 \%$ for as-deposited TiAlBSiN coating and $68 \%$ for the coating annealed at $900{ }^{\circ} \mathrm{C}$.

The relatively low hardness of the amorphous coating could be associated with existence of the local areas with high ratio of free volume that in turn promote the decrease of density of the amorphous phase. The more possible reason is a low density of the short range ordered species (bonds) with high strength. In earlier works, the hardness of the amorphous TiAlBSiN coatings was reported to be $\sim 15 \mathrm{GPa}$ [81], $21 \mathrm{GPa}[80]$ and $17.1 \pm 0.5 \mathrm{GPa}$ [21] and the growth of hardness was observed for coatings reported in [21] and [81] up to $21 \mathrm{GPa}$ after annealing at $700^{\circ} \mathrm{C}$ and up to $\sim 20 \mathrm{GPa}$ after annealing at $800{ }^{\circ} \mathrm{C}$, respectively, but the hardness decreased for higher annealing temperatures [80].

The transformation of the amorphous phase with formation of the nanocomposite structure dramatically changes the mechanical behavior of the system $[82,83]$. The interaction between the grains hinders 
the generation of dislocations (grain size is smaller than the length of dislocation) and prevents cracks propagation due to the grain boundary enhancement and suppression of grain boundary sliding in nanocomposite coatings with small grain size. In our case the hardness increase could be attributed to the combined effects of composite structure and free volume annihilation due to the structure transformation.

Besides, it was understood that the enhanced hardness $\mathrm{H}$ is not a single important property of the hard nanocomposite coatings [84]. For many applications the toughness (resistance to plastic deformation, $\mathrm{H}^{3} / \mathrm{E}_{\mathrm{r}}^{2}$ ratio) and elastic strain prior to the plastic deformation $\left(\mathrm{H} / \mathrm{E}_{\mathrm{r}}\right)$ of the protective coating is more important than its extremely high hardness $\mathrm{H}$ which were calculated to be $\mathrm{H}^{3} / \mathrm{E}_{\mathrm{r}}^{2}=0.322 \mathrm{GPa}$ and $\mathrm{H} / \mathrm{E}_{\mathrm{r}}=$ 0.115 for the annealed coating and $H^{3} / \mathrm{E}_{\mathrm{r}}^{2}=0.111 \mathrm{GPa}$ and $\mathrm{H} / \mathrm{E}_{\mathrm{r}}=$ 0.0856 for the as-deposited coating. The influence of elasticity in combination with hardness is a reliable indicator of the wear resistance [85, 86]. Thus, higher $\mathrm{H} / \mathrm{E}_{\mathrm{r}}$ ratio of the coating after annealing is an indication of the coating's ability to resist mechanical degradation and failure in a tribo-contact events because the contact can remain elastic at higher stresses during the external impact. Relatively high value of the $H^{3} / \mathrm{E}_{\mathrm{r}}^{2}$ ratio of the nanocomposite coating implies the increased ability of a material to absorb energy during deformation up to fracture. This in turn leads to the increase of the coating resistance to the formation of cracks and hence to lower brittleness. Moreover, the possible reason of the increase of the resistance to cracking of the TiAlSiBN coating after annealing could be associated with the generation of the compressive macro stresses due to the higher thermal expansion coefficient of the coating with respect to the silicon substrate $[87,88]$.

It is widely acknowledged that surface properties have great influence on the tribological properties of coatings at initial stage of friction and wear and in consequence on behavior of the whole system. In order to carry out an in-depth characterization of the mechanical properties of the coating surface layer, nanoindentation measurements were conducted using a multiple load function applied to a diamond Berkovich tip with maximum loads from $0.05 \mu \mathrm{N}$ to $2 \mathrm{mN}$. The hardness and reduced elastic modulus values of each multi-cycle load plotted as a function of penetration depth for both TiAlBSiN as-deposited coating and those after annealing at $900{ }^{\circ} \mathrm{C}$ are displayed in Fig. 8. It is well visible, that the $\mathrm{H}$ and $\mathrm{E}_{\mathrm{r}}$ of the amorphous layer of the coating after annealing are higher than those of as-deposited one. As was already shown, both layers are in the amorphous state. Thus, the increase of hardness after annealing could be associated with the change in the chemical short range order due to the interdiffusion in this part of the coating. The higher hardness of the surface of the annealed coating is due to its densification with high strength bonds that is in agreement with XPS results (the bond strength in $\mathrm{kJ} / \mathrm{mol}$ are: $\mathrm{Al}-\mathrm{O} \approx 514$, Si-O $\approx 800$, $\mathrm{Ti}-\mathrm{O} \approx 672$, $\mathrm{Ti}-\mathrm{N} \approx 476, \mathrm{~B}-\mathrm{O} \approx 715$ ).

The relatively high ratio $\mathrm{H} / \mathrm{E}_{\mathrm{r}} \geq 0.1$, the high elastic recovery We $\geq 60 \%$ and the dense, void-free microstructure of TiAlBSiN coatings before and after annealing at $900{ }^{\circ} \mathrm{C}$ satisfy the needs for flexible hard nanocomposite coatings [87] and could therefore have a huge application potential.

\subsection{Tribological tests}

In order to optimize the tribological behavior of the coating it is particularly useful to analyze the tribological changes at the nano- and micro scale and to study separately the mechanical and chemical changes as well as material transfer taking place in the contact. A typical wear mark on the coating's surface, is of the size $5 \mu \mathrm{m} \times 5 \mu \mathrm{m}$, which is generated at a normal load of $1000 \mu \mathrm{N}$ for one scan cycle is shown in Fig. 9(a, d). The indentation depth in the film normal direction during the wear test did not exceed $25 \mathrm{~nm}$ that corresponds to the depth of the amorphous oxide layer. The analysis of the wear volume after the nanowear tests has revealed the higher wear volume $0.3818 \mu \mathrm{m}^{3}$ of the annealed coating than $0.046 \mu \mathrm{m}^{3}$ of the as-prepared coating. Fig. 9(b, e) show wear edge of the corresponding wear tracks of the
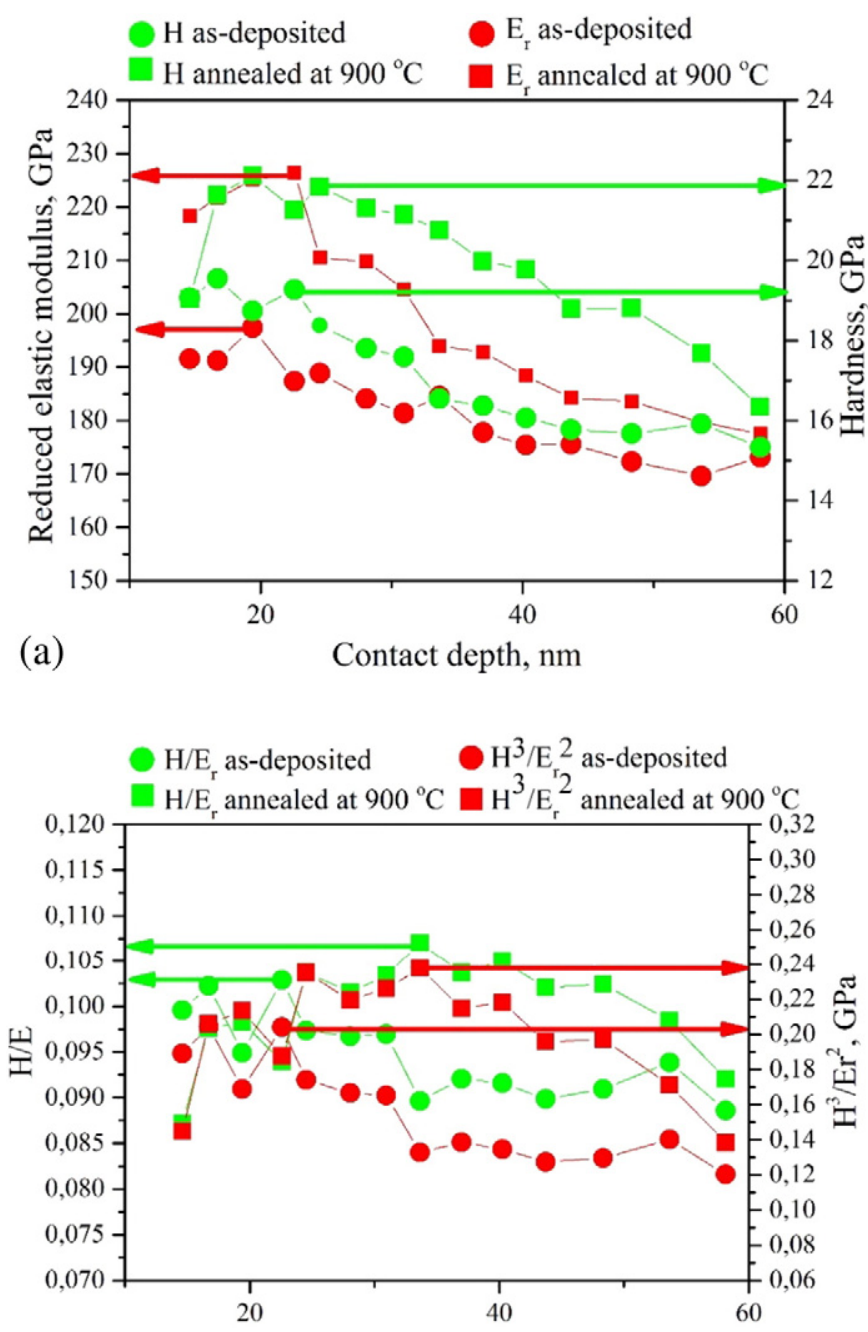

(b)

Contact depth, nm

Fig. 8. Hardness and reduced elastic modulus as the function of the contact depth (a) and variation of the ratio $\mathrm{H} / \mathrm{E}_{\mathrm{r}}$ and $\mathrm{H}^{3} / \mathrm{E}_{\mathrm{r}}^{2}$ as the function of contact depth (b) of the asdeposited and annealed at $900{ }^{\circ} \mathrm{C}$ TiAlBSiN coatings on silicon wafer substrate.

coatings where wear debris is clearly observed. The translation of the indenter along the sliding direction leads to the material removal due to the abrasive wear and generation of the wear debris. The morphology of the debris is different for the as-deposited and annealed coating. Many round-shaped $<50 \mathrm{~nm}$ size wear debris was observed at the edge of the wear track of the as-deposited coating. The formation of the nanosized wear debris could be attributed to the high concentration of the local areas with free volume, which separates the areas with high density. A biased accumulation of the local strains incurred through an inelastic shear distortion of local areas with high density and the redistribution of the free volume promotes the plastic deformation of the surface with the generation of local areas with high density as wear debris. Further densification and annihilation of free volume of the surface layer after annealing at $900{ }^{\circ} \mathrm{C}$ led to the formation of the cutting type debris with flake-like morphology $<500 \mathrm{~nm}$ size. The delamination of the wear debris (crack propagation) occurs at the boundary regions of the high density areas. The boundary regions could be composed of free volume or/and low shear strength phase.

Fig. 9c,f shows EDS mapping of $\mathrm{O}$ at the wear edges of the asdeposited (c) and annealed coating (f). Due to the well visible contrast it is evident that the wear debris of both coatings is based on Me-Met$O$ phase. According to XPS analysis of the as-deposited coating surface, the base $\mathrm{O}$ containing phases are non-stoichiometric $\mathrm{Al}_{2} \mathrm{O}_{3}$ and $\mathrm{B}_{2} \mathrm{O}_{3}$. $\mathrm{B}_{2} \mathrm{O}_{3}$ has high ionic potential and due to the pronounced screening of 

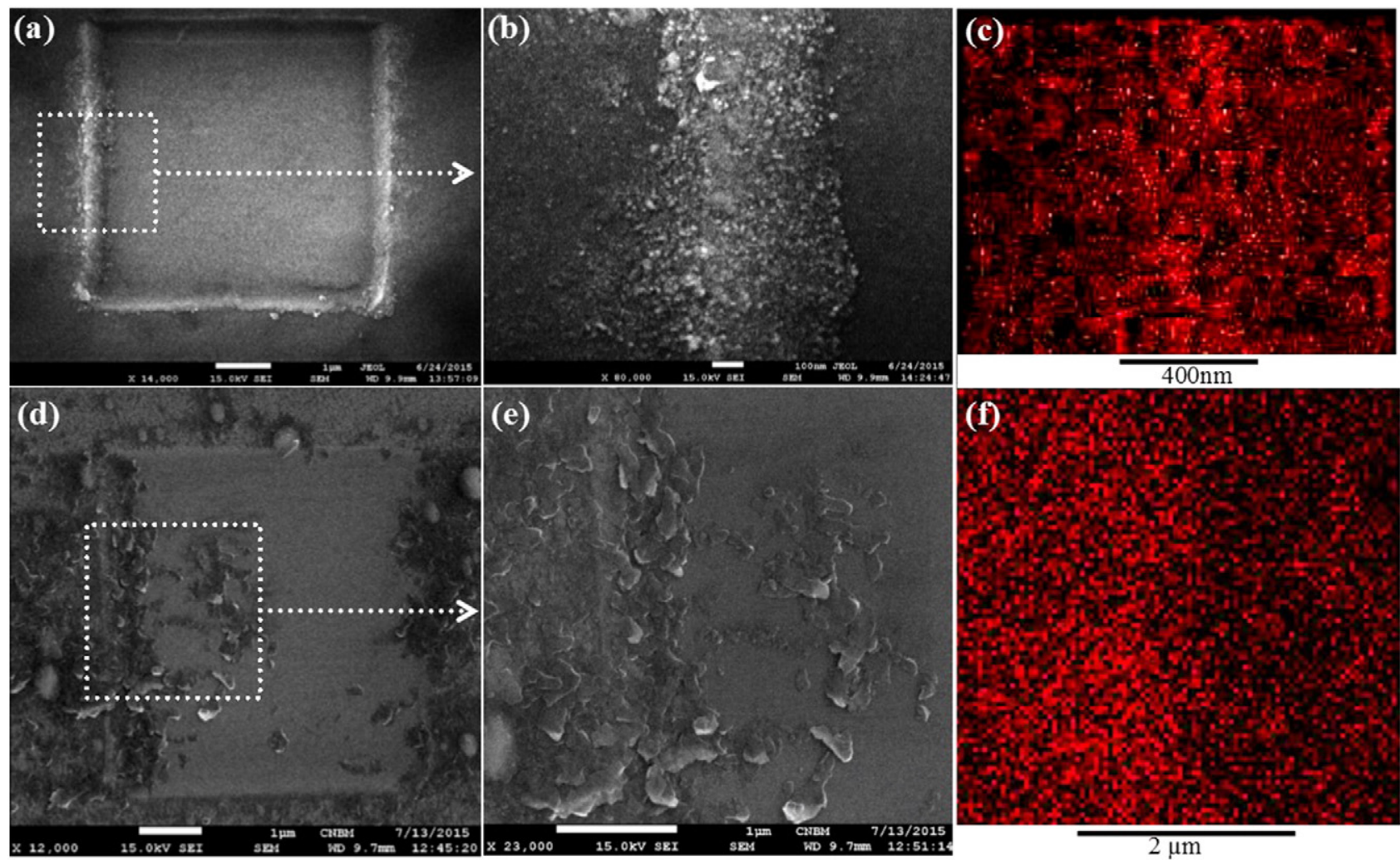

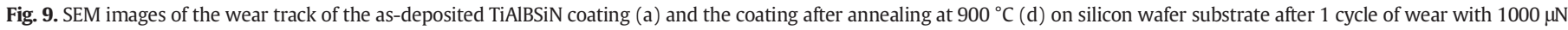
normal load, and corresponding SEM images (b, e) of wear edge with results of EDS mapping of O (c, f).

the cation by the surrounding anions the cations interact very little with other cations which allows for easy shearing [89]. Further annealing of the coating promotes $\mathrm{Al}_{2} \mathrm{O}_{3}$ overgrowth, which has low ionic potential because its cations constantly interact with each other and form strong covalent or ionic bonds that make them very strong and hard to shear, and simultaneous release of $\mathrm{B}$ (volatile boric acid $\mathrm{H}_{3} \mathrm{BO}_{3}$ ) have caused higher wear of the coating. The amount of lubricious $\mathrm{H}_{3} \mathrm{BO}_{3}[90]$ is too low to separate asperities of the contacting surfaces and hence $\mathrm{H}_{3} \mathrm{BO}_{3}$ did not strongly effect the wear behavior of the surface layer. This facts coupled with the EDS mapping indicate that the wear debris more probably based on $\mathrm{Al}_{2} \mathrm{O}_{3}$.
Due to more pronounced relationship and higher values of the $\mathrm{H} / \mathrm{Er}$ and $\mathrm{H}^{3} / \mathrm{E}_{\mathrm{r}}^{2}$ ration at depth $25 \mathrm{~nm}$, the annealed coating could demonstrate much better wear resistance at this depth due to the relatively higher elastic strain-to-fracture and higher resistance to crack propagation, hence the contact can remain elastic at higher stresses during wear.

Friction and wear tests at the micro-scale were performed on the reciprocating ball-on-block tribometer. Fig. 10 depicts the variations in friction coefficient, oven temperature, sample temperature, friction force and penetration depth of TiAlBSiN coating with sliding time, sliding distance and laps. The mean value of the friction coefficient was

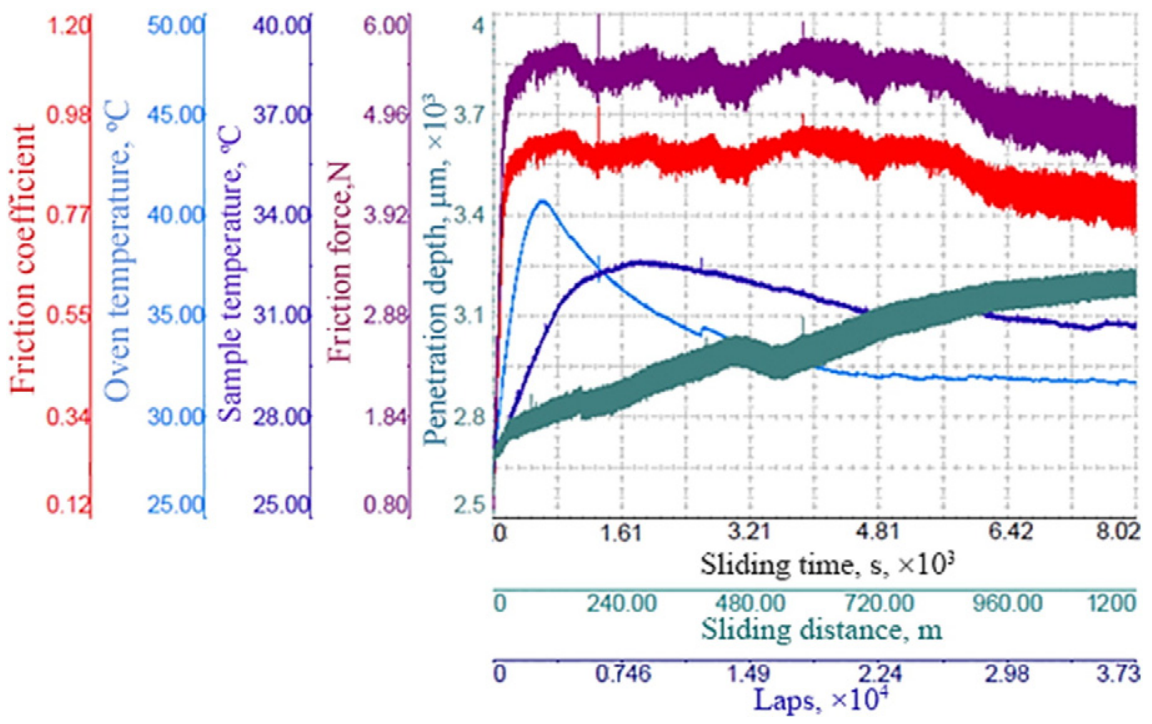

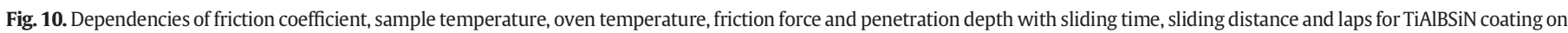
steel substrate against $\mathrm{Al}_{2} \mathrm{O}_{3}$ ball at room temperature. 

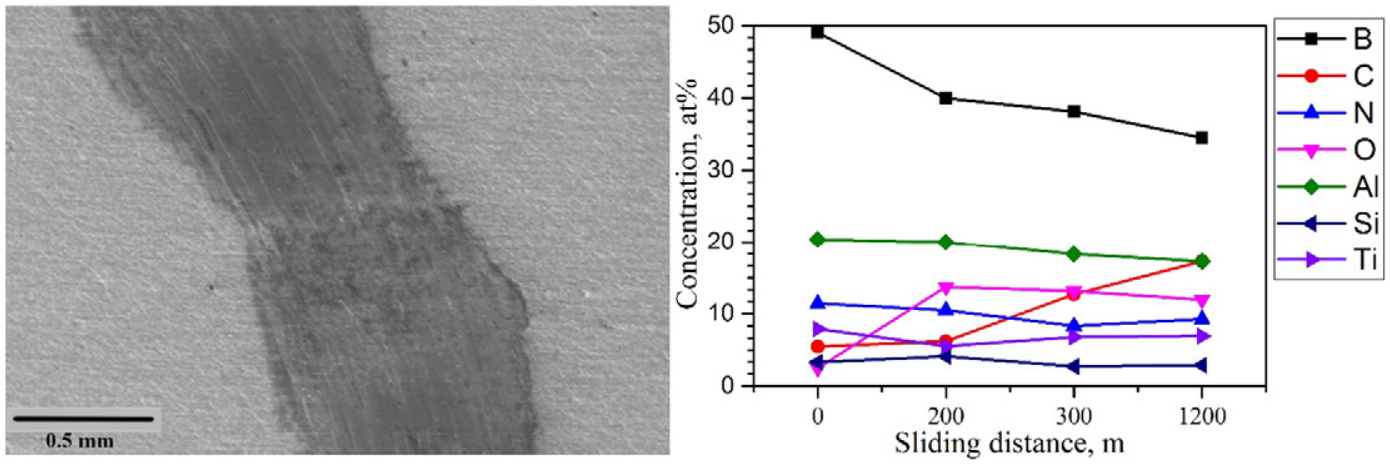

Fig. 11. Surface morphology of the wear tracks on TiAlBSiN coating on steel substrate sliding against $\mathrm{Al}_{2} \mathrm{O}_{3}$ (a) and EDS results at different stages of the wear test (b).

calculated to be 0.871 while wear rare was $0.2946 \mu \mathrm{m}^{3} / \mathrm{Nm}$. The friction coefficient starts at relatively low values fluctuating for $66 \mathrm{~min}$ and suddenly rises to a high value after $500 \mathrm{~m}$ of sliding.

In order to understand the wear mechanisms, observations of the wear track was carried out by means of SEM-EDS. Fig. 11a shows wear track of the TiAlBSiN coating after wear test at room temperature after $500 \mathrm{~m}$ of sliding. No wear debris was observed at the wear edge of the track. Nevertheless, wear debris of high hardness but low ductility trapped in the contact area act as an abrasive third body and thus increase wear and cause abrasion scars in the wear track after $500 \mathrm{~m}$ of sliding and increasing of the coefficient of friction as well. According to the results of EDS inspection of the wear track after 200, 300 and $1200 \mathrm{~m}$ of sliding distance (Fig. 11), a significant increase of $\mathrm{O}$ concentration and decrease of $\mathrm{B}$ at the initial stage of sliding was detected. Moreover, the sample temperature increases after $200 \mathrm{~m}$ of sliding.

Thus, it is evident that the tribo-oxidation stimulated by the complex chemical and thermal interactions occurs within the sliding contact zone during sliding. The reported fluctuation of the friction coefficient is related to the surface status of tribo-contact region. The high temperature in tribo-contact promotes the oxidation of $\mathrm{B}$ and $\mathrm{Al}$ with formation of the corresponding oxides. The high friction coefficient at the initial stage of friction could be attributed to the generation of hard shear $\mathrm{Al}_{2} \mathrm{O}_{3}$ third body wear debris. Further temperature increase stimulates $\mathrm{B}$ oxidation to low shear $\mathrm{B}_{2} \mathrm{O}_{3}$ slightly decreases friction coefficient. The loss of $\mathrm{B}$ could be associated with the formation of $\mathrm{H}_{3} \mathrm{BO}_{3}$ and its decomposition after increase of temperature in tribo-contact. This assumptions are in agreement with the standard enthalpy of formation for the mentioned substances $\left(\Delta \mathrm{H}_{\mathrm{Al} 2 \mathrm{O} 3}=-1676 \mathrm{~kJ} / \mathrm{mol}\right.$, $\left.\Delta \mathrm{H}_{\mathrm{B} 2 \mathrm{O} 3}=-1244 \mathrm{~kJ} / \mathrm{mol}, \Delta \mathrm{H}_{\mathrm{H} 3 \text { воз }}=-1072 \mathrm{~kJ} / \mathrm{mol}[42]\right)$.

\section{Conclusions}

Amorphous TiAlBSiN coating with sacrificial barrier layer was grown by sequential reactive and non-reactive magnetron sputtering. The coating and the barrier layer shows dense, void-free and featureless microstructure after deposition. To explain the structural transformations during annealing at $900{ }^{\circ} \mathrm{C}$ in ambient air the AFM, SEM, TEM, HR-TEM, EDS, XPS and Raman spectroscopy measurements were performed. Obtained results show the changes in topological and chemical shortrange order during the amorphous phase transformation, which lead to the phase separation of the amorphous TiAlBSiN coating and the formation of a three dimensional nc- $\mathrm{TiAl}_{3} / \mathrm{a}-\mathrm{SiBN}(\mathrm{O})$ nanocomposite structure after the post-deposition annealing. The hardness of the amorphous coating increases from $15.20 \mathrm{GPa}$ up to $24.41 \mathrm{GPa}$ after annealing due to the combined effects of composite structure and free volume annihilation due to structure transformation. The resistance of the amorphous coating to plastic deformation $\left(\mathrm{H}^{3} / \mathrm{E}_{\mathrm{r}}^{2}\right)$ ratio and elastic strain prior to the plastic deformation $\left(\mathrm{H} / \mathrm{E}_{\mathrm{r}}\right)$ and the elastic recovery were significantly improved after the formation of the nanocomposite structure. The characterization of tribological behavior of the coatings at nano- and micro-scale revealed good tribological characteristics. The reported response of the amorphous TiAlBSiN coatings to the high temperature impact makes them potential candidates for application as flexible protective coating for extreme tribological applications. The presented results are of great scientific and practical importance in the field of flexible high temperature protective coatings.

\section{Acknowledgments}

A.P. acknowledges the financial support of Erasmus Mundus EMINENCE partnership. The authors gratefully acknowledge the financial support from the research project Preludium UMO-2015/19/N/ST5/ 01764 of National Science Center. The authors are grateful to Dr. B. Scheibe from NanoBioMedical Centre for his technical help during the Raman spectroscopy experiments.

\section{References}

[1] S. Veprek, M.J.G. Veprek-Heijman, Industrial applications of superhard nanocomposite coatings, Surf. Coat. Technol. 202 (2008) 5063-5073, http://dx.doi.org/10.1016/j. surfcoat 2008.05.038.

[2] M.D. Abad, S.C. Veldhuis, J.L. Endrino, B.D. Beake, A. García-Luis, M. Brizuela, et al., Mechanical and phase stability of TiBC coatings up to $1000^{\circ} \mathrm{C}$, J. Vac. Sci. Technol. A 32 (2014) 021508, http://dx.doi.org/10.1116/1.4861365.

[3] H.A. Jehn, Multicomponent and multiphase hard coatings for tribological applications, Surf. Coat. Technol. 131 (2000) 433-440, http://dx.doi.org/10.1016/S02578972(00)00783-0.

[4] G. Fox-Rabinovich, A. Kovalev, M.H. Aguirre, K. Yamamoto, S. Veldhuis, I. Gershman, et al., Evolution of self-organization in nano-structured PVD coatings under extreme tribological conditions, Appl. Surf. Sci. 297 (2014) 22-32, http://dx.doi.org/10.1016/ j.apsusc.2014.01.052.

[5] R. Hollerweger, H. Riedl, J. Paulitsch, M. Arndt, R. Rachbauer, P. Polcik, et al., Origin of high temperature oxidation resistance of Ti-Al-Ta-N coatings, Surf. Coat. Technol. 257 (2014) 78-86, http://dx.doi.org/10.1016/j.surfcoat.2014.02.067.

[6] A.D. Pogrebnjak, I.V. Yakushchenko, A.A. Bagdasaryan, O.V. Bondar, R. KrauseRehberg, G. Abadias, et al., Microstructure, physical and chemical properties of nanostructured (Ti-Hf-Zr-V-Nb)N coatings under different deposition conditions, Mater. Chem. Phys. 147 (2014) 1079-1091, http://dx.doi.org/10.1016/j. matchemphys.2014.06.062.

[7] J. Musil, J. Vlček, P. Zeman, Hard amorphous nanocomposite coatings with oxidation resistance above $1000{ }^{\circ} \mathrm{C}$, Adv. Appl. Ceram. 107 (2008) 148-154, http://dx.doi.org/ $10.1179 / 174367508 \times 306460$

[8] J. Musil, Hard and superhard nanocomposite coatings, Surf. Coat. Technol. 125 (2000) 322-330, http://dx.doi.org/10.1016/S0257-8972(99)00586-1.

[9] J.C. Zhao, J.H. Westbrook, Ultrahigh-temperature materials for jet engines, MRS Bull. 28 (2003) 622-627.

[10] J. Hailing, Encyclopedia of tribology, Wear 150 (1991) 382, http://dx.doi.org/10. 1016/0043-1648(91)90333-P.

[11] K.A. Kuptsov, P.V. Kiryukhantsev-Korneev, A.N. Sheveyko, D.V. Shtansky, Structural transformations in TiAlSiCN coatings in the temperature range $900-1600{ }^{\circ} \mathrm{C}$, Acta Mater. 83 (2015) 408-418, http://dx.doi.org/10.1016/j.actamat.2014.10.007.

[12] K-D. Bouzakis, G. Skordaris, S. Gerardis, G. Katirtzoglou, S. Makrimallakis, M. Pappa, et al., Ambient and elevated temperature properties of TiN, TiAIN and TiSiN PVD films and their impact on the cutting performance of coated carbide tools, Surf. Coat. Technol. 204 (2009) 1061-1065, http://dx.doi.org/10.1016/j.surfcoat.2009. 07.001.

[13] P.V. Kiryukhantsev-Korneev, J.F. Pierson, J.P. Bauer, E.A. Levashov, D.V. Shtansky, Hard Cr-Al-Si-B-(N) coatings with oxidation resistance up to $1200{ }^{\circ} \mathrm{C}$, Glas. Phys. Chem. 37 (2011) 411-417, http://dx.doi.org/10.1134/S1087659611040109.

[14] H.C. Barshilia, S. Acharya, M. Ghosh, T.N. Suresh, K.S. Rajam, M.S. Konchady, et al., Performance evaluation of TiAlCrYN nanocomposite coatings deposited using 
four-cathode reactive unbalanced pulsed direct current magnetron sputtering system, Vacuum 85 (2010) 411-420, http://dx.doi.org/10.1016/j.vacuum.2010.08.003.

[15] M.A. Baker, S. Klose, C. Rebholz, A. Leyland, A. Matthews, Evaluating the microstructure and performance of nanocomposite PVD TiAlBN coatings, Surf. Coat. Technol. 152 (2002) 338-343.

[16] C. Rebholz, M.A. Monclus, M.A. Baker, P.H. Mayrhofer, P.N. Gibson, A. Leyland, et al Hard and superhard TiAlBN coatings deposited by twin electron-beam evaporation, Surf. Coat. Technol. 201 (2007) 6078-6083, http://dx.doi.org/10.1016/j.surfcoat. 2006.08.121.

[17] M.A. Baker, C. Rebholz, A. Leyland, A. Matthews, Electron spectroscopic studies of nanocomposite PVD TiAlBN coatings, Vaccum 67 (2002) 471-476

[18] D.V. Shtansky, K. Kaneko, Y. Ikuhara, E.A. Levashov, Characterization of nanostructured multiphase Ti-Al-B-N thin films with extremely small grain size, Surf. Coat. Technol. 148 (2001) 206-215, http://dx.doi.org/10.1016/S0257-8972(01)01341-X.

[19] H. Abu Samra, A. Kumar, J. Xia, T. Staedler, X. Jiang, Development of a new generation of amorphous hard coatings based on the $\mathrm{Si}-\mathrm{B}-\mathrm{C}-\mathrm{N}-\mathrm{O}$ system for applications in extreme conditions, Surf. Coat. Technol. 223 (2013) 52-67, http://dx.doi.org/10. 1016/j.surfcoat.2013.02.028.

[20] H. Zeman, J. Musil, J. Vlček, P.H. Mayrhofer, C. Mitterer, Thermal annealing of sputtered Al-Si-Cu-N films, User Model. User-Adap. Inter. 72 (2003) 21-28, http:// dx.doi.org/10.1016/S0042-207X(03)00094-0.

[21] H. Fager, J.M. Andersson, J. Jensen, J. Lu, L. Hultman, Thermal stability and mechanical properties of amorphous coatings in the Ti-B-Si-Al-N system grown by cathodic arc evaporation from TiB2, Ti33Al67, and Ti85Si15 cathodes, J. Vac. Sci. Technol. A 32 (2014) 061508, http://dx.doi.org/10.1116/1.4897170

[22] S. Zhang, L. Wang, Q. Wang, M. Li, A superhard CrAlSiN superlattice coating deposited by a multi-arc ion plating: II. Thermal stability and oxidation resistance, Surf. Coat. Technol. 214 (2013) 153-159, http://dx.doi.org/10.1016/j.surfcoat.2012.05.143.

[23] M. Mikula, B. Grančič, M. Drienovský, L. Satrapinskyy, T. Roch, Z. Hájovská, et al., Thermal stability and high-temperature oxidation behavior of $\mathrm{Si}-\mathrm{Cr}-\mathrm{N}$ coatings with high content of silicon, Surf. Coat. Technol. 232 (2013) 349-356, http://dx. doi.org/10.1016/j.surfcoat.2013.05.034.

[24] C. Paternoster, A. Fabrizi, R. Cecchini, S. Spigarelli, P.V. Kiryukhantsev-Korneev, A Sheveyko, Thermal evolution and mechanical properties of hard $\mathrm{Ti}-\mathrm{Cr}-\mathrm{B}-\mathrm{N}$ and Ti-Al-Si-B-N coatings, Surf. Coat. Technol. 203 (2008) 736-740, http://dx.doi.org/ 10.1016/j.surfcoat.2008.08.013.

[25] H. Ollendorf, D. Schneider, A comparative study of adhesion test methods for hard coatings, Surf. Coat. Technol. 113 (1999) 86-102, http://dx.doi.org/10.1016/S02578972(98)00827-5.

[26] A. Abid, R. Bensalem, J.B. Sealy, The Thermal Stability of AIN, J. Mater. Res. 21 (1986) $8-11$

[27] C. Lin, F. Lu, Oxidation Behavior of AlN Films at High Temperature Under Controlled Atmosphere, 28 (2008) 691-698, http://dx.doi.org/10.1016/j.jeurceramsoc.2007.07.015

[28] P.H. Mayrhofer, C. Mitterer, J.G. Wen, J.E. Greene, I. Petrov, Self-organized nanocolumnar structure in superhard TiB2 thin films, Appl. Phys. Lett. 86 (2005) 1-3, http://dx.doi.org/10.1063/1.1887824.

[29] H. Search, C. Journals, A. Contact, M. Iopscience, I.P. Address, Study of oxidation of TiSi2 thin film by XPS, Jpn. J. Appl. Phys. 23 (1984) 1560-1567.

[30] J. Caicedo, C. Amaya, L. Yate, O. Nos, M. Gomez, P. Prieto, Hard coating performance enhancement by using $[\mathrm{Ti} / \mathrm{TiN}] \mathrm{n},[\mathrm{Zr} / \mathrm{ZrN}] \mathrm{n}$ and $[\mathrm{TiN} / \mathrm{ZrN}] \mathrm{n}$ multilayer system, Mater. Sci. Eng. B 171 (2010) 56-61, http://dx.doi.org/10.1016/j.mseb.2010.03.069.

[31] H. Moreno, J. Caicedo, C. Amaya, G. Cabrera, L. Yate, W. Aperador, et al., Improvement of the electrochemical behavior of steel surfaces using a TiN[BCN/BN]n/c-BN multilayer system, Diam. Relat. Mater. 20 (2011) 588-595, http://dx.doi.org/10. 1016/j.diamond.2010.11.013.

[32] O.N. Grigor'ev, I.A. Podchernyaeva, A.D. Panasyuk, V.V. Varyukhno, Heat- and wearresistant composite materials and coatings on AlN-TiB2, Refract. Ind. Ceram. 45 (2004) 373-378.

[33] D. Philippon, V. Godinho, P.M. Nagy, M.P. Delplancke-Ogletree, A. Fernández, Endurance of TiAlSiN coatings: effect of $\mathrm{Si}$ and bias on wear and adhesion, Wear 270 (2011) 541-549, http://dx.doi.org/10.1016/j.wear.2011.01.009.

[34] H. Fager, G. Greczynski, J. Jensen, J. Lu, L. Hultman, H. Fager, et al., Growth and Properties of Amorphous Ti-B-Si-N Thin Films Deposited by Hybrid HIPIMS/DC-Magnetron Co-Sputtering from TiB2 and Si Targets, 2014 442-447.

[35] M. Pfeiler, J. Zechner, M. Penoy, C. Michotte, C. Mitterer, M. Kathrein, Improved oxidation resistance of TiAlN coatings by doping with Si or B, Surf. Coat. Technol. 203 (2009) 3104-3110, http://dx.doi.org/10.1016/j.surfcoat.2009.03.036.

[36] J. Vlček, Š. Potocký, J. Čížek, J. Houška, M. Kormunda, P. Zeman, et al., Reactive Magnetron Sputtering of Hard Si - B - C - N Films with a High-Temperature Oxidation Resistance, 2008 1513, http://dx.doi.org/10.1116/1.2049298.

[37] A.A. Onoprienko, V.I. Ivashchenko, I.A. Podchernyaeva, O.Y. Khizhun, I.I. Timofeeva, O.A. Butenko, Production of Ti-Al-Si-B-N films by magnetron sputtering and study of their mechanical properties, Powder Metall. Met. Ceram. 53 (2014) 353-358, http://dx.doi.org/10.1007/s11106-014-9623-1.

[38] W.C. Oliver, G.M. Pharr, Improved technique for determining hardness and elastic modulus using load and displacement sensing indentation experiments, J. Mater. Res. 7 (1992) 1564-1580, http://dx.doi.org/10.1557/JMR.1992.1564.

[39] A.M. Korsunsky, M.R. McGurk, S.J. Bull, T.F. Page, On the hardness of coated systems, Surf. Coat. Technol. 99 (1998) 171-183, http://dx.doi.org/10.1016/S02578972(97)00522-7.

[40] J. Musil, J. Šuna, The role of energy in formation of sputtered nanocomposite films, Mater. Sci. Forum 502 (2005) 291-296, http://dx.doi.org/10.4028/www.scientific. net/MSF.502.291.

[41] A.V. Pshyk, L.E. Coy, L. Yate, K. Załęski, G. Nowaczyk, A.D. Pogrebnjak, et al., Combined reactive/non-reactive DC magnetron sputtering of high temperature composite AlN-TiB2-TiSi2, Mater. Des. 94 (2016) 230-239, http://dx.doi.org/10.1016/j. matdes.2015.12.174.

[42] D.R. Lide, CRC Handbook of Chemistry and Physics, CRC Press, Boca Raton, 2005.

[43] S.S. Lee, E. Lee, S.H. Kim, B.K. Lee, S.J. Jeong, Non-stoichiometric AlO $\times$ Films Prepared by Chemical Vapor Deposition Using Dimethylaluminum Isopropoxide as Single Precursor and Their Non-volatile Memory Characteristics, 33 (2012) 2207-2212.
[44] J. Prokop, A. Kukunin, M. Pratzer, H. Elmers, Oxidation-driven Changes of the Inplane Magnetic Surface Anisotropies of the Fe (110)/Al Interface, 265 (2003) 60-68, http://dx.doi.org/10.1016/S0304-8853(03)00225-7.

[45] A.V. Naumkin, A. Kraut-Vass, S.W. Gaarenstroom, C.J. Powell, NIST Standard Reference Database 20, 2012 (http://srdata.nist.gov/xps/Default.aspx).

[46] R. Methaapanon, S.F. Bent, Comparative study of titanium dioxide atomic layer deposition on silicon dioxide and hydrogen-terminated silicon, J. Phys. Chem. C 114 (2010) 10498-10504, http://dx.doi.org/10.1021/jp1013303.

[47] R.L. Kurtz, Comparison of Ti $2 \mathrm{p}$ core-level peaks from $\mathrm{TiO}_{2}, \mathrm{Ti}_{2} \mathrm{O}_{3}$, and Ti metal, by XPS, Surf. Sci. Spectra 5 (1998) 179-181.

[48] F. Kieckow, C. Kwietniewski, E.K. Tentardini, A. Reguly, I.J.R. Baumvol, XPS and ion scattering studies on compound formation and interfacial mixing in TiN/T nanolayers on plasma nitrided tool steel, Surf. Coat. Technol. 201 (2006) 3066-3073, http://dx.doi.org/10.1016/j.surfcoat.2006.06.020.

[49] N. Gritsenko, V.A. Kostikov, Y. P., Romanov, SiOx as a model medium with largescale potential fluctuation, Lett. J. Exp. Theor. Phys. 34 (1981) 3-6.

[50] E. Piskorska, K. Lawniczak-jablonska, I.N. Demchenko, R. Minikayev, E. Benko, Characterization of the c-BN/TiC, $\mathrm{Ti}_{3} \mathrm{SiC}_{2}$ Systems by Element Selective Spectroscopy, J. Alloys Compd. 382 (2004) 187-194, http://dx.doi.org/10.1016/j.jallcom.2004.05. 043.

[51] Y. Wang, M. Trenary, Surface chemistry of boron oxidation. 2. The reactions of $\mathrm{B}_{2} \mathrm{O}_{2}$ and $\mathrm{B}_{2} \mathrm{O}_{3}$ with boron films grown on Ta(ll0), Chem. Mater. 5 (1993) 199-205, http:// dx.doi.org/10.1021/cm00026a008.

[52] P.H. Mayrhofer, C. Mitterer, J.G. Wen, I. Petrov, J.E. Greene, Thermally Induced Selfhardening of Nanocrystalline Ti - B - N Thin Films, 2006 044301, http://dx.doi org/10.1063/1.2222406.

[53] C. Bindal, A. Erdemir, Ultralow friction behavior of borided steel surfaces after flash annealing, Appl. Phys. Lett. 923 (1995) 923, http://dx.doi.org/10.1063/1.116232.

[54] B. Vincent Crist, Handbooks of monochromatic XPS spectra volume 1 - the elements and native oxides, Handb. Elem. Nativ. Oxides, 1, 1999 1-43 (Handbooks of Monochromatic XPS Spectra)

[55] V. Crist, Fundamental XPS data from pure elements, pure oxides, and chemical compounds, Handb. Monochromatic XPS Spectra - Elem. Nativ. Oxides, 20002 (http:// www.xpsdata.com/handbook.htm).

[56] Thermo Fisher Scientific, Knowledgebase, http://xpssimplified.com/index.php2013.

[57] M. Biesinger, X-ray Photoelectron Spectroscopy (XPS) Reference Pages, http://www xpsfitting.com 2015

[58] A. Joshi, H.S. Hu, Oxidation behavior of titanium-aluminium nitrides, Surf. Coat. Technol. 76-77 (1995) 499-507, http://dx.doi.org/10.1016/0257-8972(95)02566-9.

[59] C. Lin, G.W. Yang, B.X. Liu, Prediction of solid-state amorphization in binary meta systems, Phys. Rev. B 61 (2000) 15-18.

[60] J.P. Chu, C.T. Liu, T. Mahalingam, S.F. Wang, M.J.O. Keefe, B. Johnson, et al., Annealinginduced full amorphization in a multicomponent metallic film, Phys. Rev. B 69 (2008) 1-4, http://dx.doi.org/10.1103/PhysRevB.69.113410.

[61] M. Stoehr, C.S. Shin, I. Petrov, J.E. Greene, Raman scattering from TiNx $(0.67<x<1.00)$ single crystals grown on $\mathrm{MgO}(001)$, J. Appl. Phys. 110 (2011) 0-4, http://dx.doi.org/10.1063/1.3651381.

[62] C.P. Constable, J. Yarwood, W.-D. Münz, Raman microscopic studies of PVD hard coatings, Surf. Coat. Technol. 116-119 (1999) 155-159, http://dx.doi.org/10.1016 S0257-8972(99)00072-9.

[63] G.E. Abrosimova, Evolution of the structure of amorphous alloys, Physics-Uspekhi 54 (2011) 1227-1242, http://dx.doi.org/10.3367/UFNe.0181.201112b.1265.

[64] Z.H. Stachurski, On structure and properties of amorphous materials, Materials (Basel) 4 (2011) 1564-1598, http://dx.doi.org/10.3390/ma4091564.

[65] D. Srolovitz, K. Maeda, V. Vitek, T. Egami, Structural defects in amorphous solids statistical analysis of a computer model, Philos. Mag. A. 44 (1981) 847-866.

[66] N. Schalk, J.F.T.S. Fotso, D. Holec, A. Fian, Microstructure, mechanical and optica properties of TiAlON coatings sputter-deposited with varying oxygen partial pressures, J. Phys. D. Appl. Phys. 49 (2016) 25307, http://dx.doi.org/10.1088/00223727/49/2/025307.

[67] H.C. Barshilia, Solar energy materials \& solar cells growth, characterization and performance evaluation of Ti/AITiN/AITiON/AITiO high temperature spectrally selective coatings for solar thermal power applications, Sol. Energy Mater. Sol. Cells 130 (2014) 322-330, http://dx.doi.org/10.1016/j.solmat.2014.07.037.

[68] J. Feng, S. Zhang, Y. Lu, H. Yu, L. Kang, ScienceDirect the Spectral Selective Absorbing Characteristics and Thermal Stability of SS/TiAlN/TiAlSiN/Si ${ }_{3} \mathrm{~N}_{4}$ Tandem Absorbe Prepared by Magnetron Sputtering, 111 (2015) 350-356, http://dx.doi.org/10 1016/j.solener.2014.11.005.

69] M. Naguib, M. Kurtoglu, V. Presser, J. Lu, J. Niu, M. Heon, et al., Two-dimensiona nanocrystals produced by exfoliation of Ti 3AlC 2, Adv. Mater. 23 (2011) 4248-4253, http://dx.doi.org/10.1002/adma.201102306.

[70] I. Dreiling, C. Raisch, J. Glaser, D. Stiens, T. Chassé, Surface \& coatings technology characterization and oxidation behavior of MTCVD Ti - B - N coatings, Surf. Coat Technol. 206 (2011) 479-486, http://dx.doi.org/10.1016/j.surfcoat.2011.07.067.

[71] H.C. Barshilia, K.S. Rajam, Raman spectroscopy studies on the thermal stability of TiN, CrN, TiAlN coatings and nanolayered TiN/CrN, TiAlN/CrN multilaye coatings, J. Mater. Res. 19 (2004) 3196-3205, http://dx.doi.org/10.1557/JMR. 2004.0444

[72] S. Cava, S.M. Tebcherani, I.A. Souza, S.A. Pianaro, C.A. Paskocimas, E. Longo, et al. Structural characterization of phase transition of $\mathrm{Al}_{2} \mathrm{O}_{3}$ nanopowders obtained by polymeric precursor method, Mater. Chem. Phys. 103 (2007) 394-399, http://dx. doi.org/10.1016/j.matchemphys.2007.02.046.

[73] K.S. Andrikopoulos, S.N. Yannopoulos, G.A. Voyiatzis, A.V. Kolobov, M. Ribes, J. Tominaga, Raman Scattering Study of the a-GeTe Structure and Possible Mechanism for the Amorphous to Crystal Transition, J. Phys. Condens. Matter. 18 (2006) 965-979, http://dx.doi.org/10.1088/0953-8984/18/3/014.

[74] G. Gouadec, P. Colomban, Raman spectroscopy of nanomaterials: how spectra relate to disorder, particle size and mechanical properties, Prog. Cryst. Growth Charact. Mater. 53 (2007) 1-56, http://dx.doi.org/10.1016/j.pcrysgrow.2007.01.001.

[75] G.E. Abrosimova, Evolution of the structure of amorphous alloys, Physics-Uspekhi 54 (2011) 1227-1242, http://dx.doi.org/10.3367/UFNe.0181.201112b.1265. 
[76] V. Raghavan, Al-N-Ti (aluminum-nitrogen-titanium), J. Phase Equilib. Diffus. 27 (2006) 159-162, http://dx.doi.org/10.1361/154770306X97263.

[77] K. Das, P. Choudhury, S. Das, The Al-O-Ti ( aluminum-oxygen-titanium ) system, J. Phase Equilib. 23 (2002) 525-536.

78] P. Zeman, J. Musil, R. Daniel, High-temperature oxidation resistance of Ta-Si-N films with a high Si content, Surf. Coat. Technol. 200 (2006) 4091-4096, http://dx.doi.org/ 10.1016/j.surfcoat.2005.02.097.

[79] M. Mikula, T. Roch, D. Plašienka, L. Satrapinskyy, P. Švec, D. Vlčková, et al., Therma stability and structural evolution of quaternary Ti-Ta-B-N coatings, Surf. Coat Technol. 259 (2014) 698-706, http://dx.doi.org/10.1016/j.surfcoat.2014.10.009.

[80] C. Paternoster, A. Fabrizi, R. Cecchini, S. Spigarelli, P.V. Kiryukhantsev-korneev, A Sheveyko, Thermal evolution and mechanical properties of hard $\mathrm{Ti}-\mathrm{Cr}-\mathrm{B}-\mathrm{N}$ and Ti - Al - Si - B - N coatings, Surf. Coat. Technol. 203 (2008) 736-740, http:// dx.doi.org/10.1016/j.surfcoat.2008.08.013.

[81] F.V. Kiryukhantsev-Korneev, M.I. Petrzhik, A.N. Sheveiko, E.A. Levashov, D.V Shtanskii, Effect of $\mathrm{Al}, \mathrm{Si}$, and $\mathrm{Cr}$ on the thermal stability and high-temperature oxidation resistance of coatings based on titanium boronitride, Phys. Met. Metallogr. 104 (2007) 167-174, http://dx.doi.org/10.1134/S0031918X07080091.

[82] N. Li, C.H. Gao, Formation and Crystallization Kinetics of Amorphous Alloys(Beijing 2008
[83] C.A. Schuh, T.C. Hufnagel, U. Ramamurty, Mechanical behavior of amorphous alloys, Acta Mater. 55 (2007) 4067-4109, http://dx.doi.org/10.1016/j.actamat.2007.01.052.

[84] A. Leyland, A. Matthews, On the significance of the H/E ratio in wear control : a nanocomposite coating approach to optimised tribological behaviour, Wear 246 (2000) 1-11.

[85] B.D. Beake, V.M. Vishnyakov, A.J. Harris, Relationship between mechanical properties of thin nitride-based films and their behaviour in nano-scratch tests, Tribol. Int. 44 (2011) 468-475, http://dx.doi.org/10.1016/j.triboint.2010.12.002.

[86] A. Matthews, S. Franklin, K. Holmberg, Tribological coatings: contact mechanisms and selection, J. Phys. D. Appl. Phys. 40 (2007) 5463-5475, http://dx.doi.org/10. 1088/0022-3727/40/18/S07.

[87] J. Musil, Flexible hard nanocomposite coatings, RSC Adv. 5 (2015) 60482-60495, http://dx.doi.org/10.1039/C5RA09586G.

[88] P.H. Mayrhofer, F. Kunc, J. Musil, C. Mitterer, A comparative study on reactive and non-reactive unbalanced magnetron sputter deposition of TiN coatings, Thin Solid Films 415 (2002) 151-159, http://dx.doi.org/10.1016/S0040-6090(02)00511-4

[89] R. Franz, C. Mitterer, Surface \& coatings technology vanadium containing self-adaptive low-friction hard coatings for high-temperature applications : a review, Surf. Coat. Technol. 228 (2013) 1-13, http://dx.doi.org/10.1016/j.surfcoat.2013.04.034

[90] A. Erdemir, Modern Tribology Handbook, CRC, Boca Raton, 2001. 